\title{
Parametric Optimisation of High-Velocity Oxy-Fuel Nickel- Chromium-Silicon-Boron and Aluminium-Oxide Coating to Improve Erosion Wear Resistance
}

\author{
Ayyappan Susila Praveen ${ }^{1}$ and Arun Arjunan ${ }^{2}$ \\ ${ }^{1}$ Department of Mechanical Engineering, Vel Tech Rangarajan Dr. Sagunthala R\&D Institute of Science and Technology, Tamil Nadu, \\ India \\ ${ }^{2}$ School of Engineering, University of Wolverhampton, Telford Innovation Campus, Telford, TF2 9NT, United Kingdom
}

\begin{abstract}
Nickel (Ni) based alloy coatings are gaining momentum due to its superior mechanical properties contributed by the dispersion of hard carbides and borides, which is substantially influenced by the processing technique. Accordingly, this work investigates High-Velocity Oxy-Fuel (HVOF) thermal spraying of Nickel-Chromium-Silicon-Boron $(\mathrm{NiCrSiB})$ and Aluminium Oxide $\left(\mathrm{Al}_{2} \mathrm{O}_{3}\right)$ at a 60:40 (wt.\%) ratio on AISI304 stainless steel substrate. The influence of HVOF spray parameters such as oxygen, fuel, and powder feed rate in addition to standoff distance on the erosion resistance was studied. The parametric model identified the rate of powder feed and standoff distance as the two most significant parameters affecting the erosion behaviour. The optimum parametric values for oxygen, fuel and powder feed rate was identified as $260 \mathrm{lpm}, 65$ lpm and $28 \mathrm{~g} / \mathrm{min}$ respectively at a standoff distance of $250 \mathrm{~mm}$ for the highest wear resistance. The results of this study show that that $\mathrm{NiCrSiB}-\mathrm{Al}_{2} \mathrm{O}_{3} \mathrm{HVOF}$ coating features a ductile erosion behaviour and offers 1.6 times more wear resistance at a $90^{\circ}$ impact angle in comparison to $30^{\circ}$.
\end{abstract}

Keywords: High-Velocity Oxy-Fuel; Nickel-Chromium-Silicon-Boron; Aluminium Oxide; Erosion wear; Process Parameter Optimisation

\section{Introduction}

Nickel-Chromium-Silicon-Boron (NiCrSiB) coatings are used in wear, corrosion, high-temperature oxidation and heat resistance applications [1,2]. This is primarily because NiCrSiB combines mechanical, tribological and high-temperature properties further to having a low environmental impact $[3,4]$. In addition, the presence of Chromium, Silicon, and Boron aids the formation of hard 
phases in the tough nickel resulting in significant wear resistance. According to Simunovic et al. and Tobar et al. $[5,6]$, silicon and boron also reduce the melting temperature and improves the selffluxing properties which are further advantageous.

One of the fundamental areas where traditional $\mathrm{NiCrSiB}$ coatings require improvement is in hardness as it falls inferior to materials like carbides and ceramics. However, literature [7-11] on $\mathrm{NiCrSiB}$ with various additives show improved erosion and corrosion resistance. In this aspect, additives reported having shown improvements in $\mathrm{NiCrSiB}$ are Tungsten carbide, Chromium carbide, Titanium carbide, Aluminium oxide, Titanium dioxide, Silicon carbide, Cerium oxide, and Zirconium dioxide. Among these, Aluminium oxide $\left(\mathrm{Al}_{2} \mathrm{O}_{3}\right)$ provides a significant advantage due to increased wettability with Nickel (Ni) phase and low cost. According to Huo et al. [12], the addition of $\mathrm{Al}_{2} \mathrm{O}_{3}$ can refine the microstructure delivering changes to phase characteristics that provide enhanced wear resistance. Furthermore, Grewal et al. [13] after investigating $\mathrm{Ni}-\mathrm{Al}_{2} \mathrm{O}_{3}$ based composite coating found that the microhardness improved with the rise in alumina fraction.

Thermal spray coatings have attracted significant interest due to its ability to spray a range of coating powder including metallic, ceramic, composite and polymeric on a wide variety of substrate surfaces [14]. Thermal spraying has been proved as one of the best available techniques to enhance surface life against corrosion and wear behavior. Consequently, the High-Velocity Oxy-Fuel (HVOF) spraying has been gaining momentum in industries associated with thermal spraying [15]. In addition to the superior performance of the deposits applied through HVOF, the technique is also compatible with applying coatings materials featuring carbides and boron.

The HVOF thermal spraying technique performs at temperatures below $3000 \mathrm{~K}$ at a particle velocity of approximately $500 \mathrm{~m} / \mathrm{s}$. Even at these parametric values, the process delivers coatings that offer low porosity, degree of oxidation and high density, hardness, and bond strength. Furthermore, because of the flexibility of the process to be adapted to a number of substrates and powders make the process highly cost-effective [16-18]. In comparison to other competing techniques such as Twin Wire Arc Spraying (TWAS), Atmospheric Plasma Spraying (APS), HVOF coatings are identified to have minimal oxide inclusion, high amorphicity, hardness and less porosity [19-21].

The microstructure and the physical properties of the HVOF coating are highly dependent on the physical and chemical properties of the impinging particles, which in turn depends on parameters such as the nozzle design, fuel to oxygen ratio, substrate distance from nozzle, shape and size characteristics of the particle [22]. Several studies have reported highly dense and uniform coating, as a result of increasing the velocity of the particles which in turn resulted in compressed splats on the substrate surface [23-25]. Yuan et al. [26] studied the wear resistance of HVOF sprayed WC-Co 
coatings by adding submicron-sized WC particles at the splats interface and reported a decrease in wear rate and improvement in micro-hardness. Despite the popularity of HVOF spraying technique, the influence of spray parameters on coatings are often unknown and requires additional research to develop diagnostic methods [27]. Consequently, for an efficient coating, optimum parametric values associated with the HVOF process needs to be developed in conjunction with the coating composition.

Design of experiments (DoE) is a statistical tool that can be used to investigate the effect of multiple variables on resulting performance characterised by an experiment iteration [28,29]. While traditional optimisation relies on studying one variable in isolation [30,31] while keeping all others constant, DoE allows for multi-variable and objective manipulation at the same time. This significantly aids in the reduction of required experiments necessary to arrive at a meaningful optimum solution. Even though numerous methodologies such as full factorial, response surface are available, the Taguchi model is the chosen DoE approach considered in this study [32]. Numerous studies have reported the successful use of the Taguchi model for the optimization of coating related parameters [33-38], however, no literature reports attempts on $\mathrm{NiCrSiB}-\mathrm{Al}_{2} \mathrm{O}_{3}$ coating. Moreover, optimum parameters required for HVOF sprayed NiCrSiB- $\mathrm{Al}_{2} \mathrm{O}_{3}$ coating targeting Erosion Wear Loss (EWL) are not available.

Although scarce, there are some studies where $\mathrm{NiCrSiB}$ coating has been studied. However, the studies have been in combination with Tungsten carbide cobalt (WC-Co) [39,40]. Furthermore, the only study where $\mathrm{NiCrSiB}$ was combined with $\mathrm{Al}_{2} \mathrm{O}_{3}$ was by Praveen et al. [40] where a Plasma spraying technique was used. Following a comprehensive review of existing literature, it was found that these studies regarding $\mathrm{NiCrSiB}-\mathrm{Al}_{2} \mathrm{O}_{3}$ coating using $\mathrm{HVOF}$ system is nonexistent. Consequently, the optimum parameters necessary to obtain an optimum coating to improve erosionwear resistance of $\mathrm{NiCrSiB}-\mathrm{Al}_{2} \mathrm{O}_{3} \mathrm{HVOF}$ coatings are not known. In addition, the HVOF spraying technique itself has not been utilised extensively for developing either $\mathrm{NiCrSiB}$ or with $\mathrm{Al}_{2} \mathrm{O}_{3}$ combination. Accordingly, there is a gap in scientific literature relating to the metallurgical and process characterization of high-velocity oxy-fuel sprayed $\mathrm{NiCrSiB}-\mathrm{Al}_{2} \mathrm{O}_{3}$ based coatings. The study is aimed at the effect of the four most relevant parameters associated with the spraying process; $(i)$ rate of flow of oxygen, (ii) fuel flow rate, (iii) feed rate of the powder and (iv) standoff distance. Optimisation of these four variables associated with the HVOF technique is carried out using Taguchi $\mathrm{L}_{9}$ orthogonal array. Finally, the erosion wear behaviour of the optimum coating is conducted at various impact angle and the erosion mechanisms identified. 


\section{Materials and Methods}

\subsection{Coating material}

There is a significant demand for coatings that can improve the wear resistance of heavy-duty industrial components. Nickel $(\mathrm{Ni})$ based alloys have the potential to be used in this regard as they have excellent wear resistance properties. One of the most notable of these alloys is $\mathrm{NiCrSiB}$ as the Nickel matrix feature borides and carbides [41,42]. Accordingly, this work introduces gas atomised $\mathrm{NiCrSiB}$ in combination with fused and crushed aluminium oxide $\left(\mathrm{Al}_{2} \mathrm{O}_{3}\right)$ powder at $60: 40$ wt.\% ratio with composition and nominal Particle Size Distribution (PSD) as shown in Table 1.

Table 1. Material and particle characteristics of the coating powder used.

\begin{tabular}{cccc}
\hline Material & Composition (wt.\%) & PSD & Manufacturing \\
\hline $\mathrm{NiCrSiB}$ & $\mathrm{Ni}-72, \mathrm{Cr}-16, \mathrm{Si}-5, \mathrm{~B}-3$ & $-53+10 \mu \mathrm{m}$ & Gas atomisation \\
$\mathrm{Al}_{2} \mathrm{O}_{3}$ & $\mathrm{Al}_{2} \mathrm{O}_{3}(99)$ & $-45+10 \mu \mathrm{m}$ & Fused and Crushed \\
\hline
\end{tabular}

Fig. 1 shows the Scanning Electron Microscope (SEM) images obtained at $50 \mu \mathrm{m}$ for the atomized $\mathrm{NiCrSiB}$ (Fig. 1a) and fused and crushed $\mathrm{Al}_{2} \mathrm{O}_{3}$ (Fig. 1b). As can be seen, the atomization of $\mathrm{NiCrSiB}$ has resulted in a majority spherical morphology of the powder with occasional elongated particles. Furthermore, a combination of particle sizes is also visible with the majority below the sieve diameter of $45 \mathrm{\mu m}$. Overall, a near normal PSD with a combination of particle sizes are beneficial as it increases the packing density (smaller particle sizes can fill the voids created by adjacent bigger particles). This, in turn, results in a continuous and dense feedstock when used for the HVOF spraying technique adopted. Furthermore, the presence of satellite particles adhering to bigger particles are also visible, however, the limited number of these are not expected to affect the powder flowability significantly.

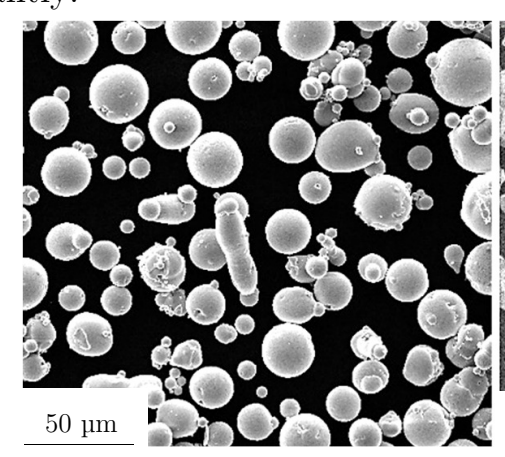

(a)

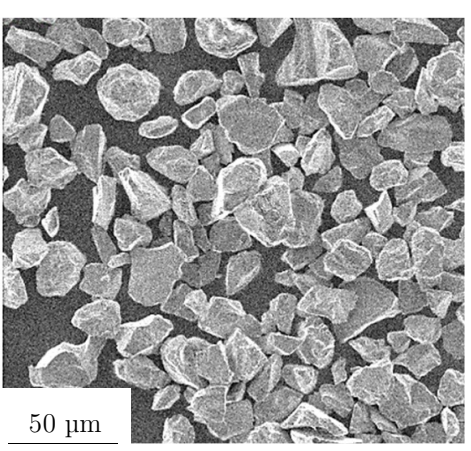

(b)

Fig. 1. Scanning electron microscopic images of the coating materials where (a) shows gas atomised $\mathrm{NiCrSiB}$ and (b) fused and crushed $\mathrm{Al}_{2} \mathrm{O}_{3}$. 
In comparison to the spherical $\mathrm{NiCrSiB}$ particles, $\mathrm{Al}_{2} \mathrm{O}_{3}$ powder can be seen as more angular in nature. This was expected as a result of the fuse and crushing technique adopted. However, a mix of particle size was obtained for $\mathrm{Al}_{2} \mathrm{O}_{3}$ as well that improve the packing density of the powder. Furthermore, the fusion and crushing techniques are known to produce powders that are consistent in size, shape, chemistry, and toughness which is often preferred for HVOF application. The feedstock composition of $\mathrm{NiCrSiB}-\mathrm{Al}_{2} \mathrm{O}_{3}$ mixture was produced by blending in a turbo missed for 60 minutes. The resulting powder composition was found to be a homogeneous mixture with good flowability.

\subsection{Substrate}

A general-purpose stainless steel AISI304 featuring a material composition as shown in Table 2 was used as the substrate for coating. The substrate specimen was processed to a $2.5 \mathrm{~cm}$ square having a thickness of $0.5 \mathrm{~cm}$ using submerged wire Electro-Discharge Machining (EDM). Following this, the coating surface was roughened to aid adhesion using corundum grits of 300-150 $\mu \mathrm{m}$. After grit blasting the specimens were acetone cleaned in an ultrasonic bath. The surface roughness of the processed samples was measured to be approximately $9 \pm 1 \mu \mathrm{m}$.

Table 2. Material composition of the substrate.

\begin{tabular}{lllllllll}
\hline Material & $\mathrm{C}$ & $\mathrm{M}$ & $\mathrm{Si}$ & $\mathrm{S}$ & $\mathrm{P}$ & $\mathrm{Cr}$ & $\mathrm{Ni}$ & $\mathrm{Fe}$ \\
\hline & & & & & & & & \\
wt. \% & 0.023 & 1.440 & 0.366 & 0.006 & 0.029 & 18.736 & 8.288 & Bal. \\
\hline
\end{tabular}

\subsection{Thermal spraying}

The deposition of $60-40$ wt.\% atomised $\mathrm{NiCrSiB}-\mathrm{Al}_{2} \mathrm{O}_{3}$ composite coating composition on the AISI304 substrate material was carried out using the High Velocity Oxy-Fuel (HVOF) thermal spraying technique. The coating experiments were carried out in a commercial high-performance water cooled HIPOJET2700 that operates on Liquified Petroleum Gas (LPG) and Oxygen. The equipment featured a powder feeder capacity of $3350 \mathrm{CC}$ and operated at a pressure of $10 \mathrm{~kg} / \mathrm{cm}^{2}$.

While numerous studies $[1,16,20,33,34,36,43]$ indicate the importance of process parameters associated with thermal spraying; pioneering works by Fang et al. [44], Murugan et al. [37] and Qin et al. [38] suggests that the flow rate of the fuel $\left(Q_{f u e l}\right)$, flow rate of oxygen $\left(Q_{\text {oxy }}\right)$, feed rate of the coating powder $\left(\dot{m}_{\text {feed }}\right)$ and standoff distance $\left(D_{\text {sof }}\right)$ between the nozzle and the substrate as the four most significant HVOF parameters that influences the properties associated with the resultant coating. Though the suggestions in literature were based on studies conducted in alternative 
materials [45-49], three primary configurations (Config.) are identified based on inhouse trial experiments to study the influence on the resulted coating as shown in Table 3. The thickness of deposition is kept at $250 \pm 30 \mu \mathrm{m}$ for all tests. Based on the three configurations, the Taguchi $\mathrm{L}_{9}$ orthogonal array was used to generate the DoE based optimisation algorithm.

Table 3 High Velocity Oxy-Fuel (HVOF) process parameters considered at three different configurations.

\begin{tabular}{clcccc}
\hline Symbol & Parameters & Range & Config. 1 & Config. 2 & Config. 3 \\
\hline A & $Q_{\text {oxy }}(\mathrm{lpm})$ & $220-260$ & 220 & 240 & 260 \\
B & $Q_{\text {fuel }}(\mathrm{lpm})$ & $55-65$ & 55 & 60 & 65 \\
C & $\dot{m}_{\text {feed }}(\mathrm{g} / \mathrm{min})$ & $28-36$ & 28 & 32 & 36 \\
$\mathrm{D}$ & $D_{\text {sof }}(\mathrm{mm})$ & $150-250$ & 150 & 200 & 250 \\
\hline
\end{tabular}

\subsection{Erosion wear}

The primary interest when it comes to the performance of the coated surface was its erosion resistance under conditions experienced within a power plant economizer or low temperature superheater tubes operating at $450{ }^{\circ} \mathrm{C}$. Resistance to erosion is characterized using erosion wear rate $(\mathrm{g} / \mathrm{g})$ calculated as the ratio of mass lost during erosion in grams to the mass of the erodent particle in grams. The mass of erosion wear loss is determined by weighing the coated sample before and after the erosion wear test. Mass of the erodent particle is the product of erodent feed rate $(\mathrm{g} / \mathrm{min})$ and testing time (min). In this study, the erosion wear rate of the $\mathrm{HVOF}$ sprayed $\mathrm{NiCrSiB}-\mathrm{Al}_{2} \mathrm{O}_{3}$ coating are characterised at a temperature of $450{ }^{\circ} \mathrm{C}$ at three different impact angles of $30^{\circ}, 60^{\circ}$ and $90^{\circ}$ as shown in Fig. 2. The experiments were carried out satisfying the ASTMG76-18 [50] guidelines using solid particles impingement using gas jets. The tests were carried out using the hot gas jet erosion testing machine manufactured by Ducom Instruments featuring a nozzle diameter of $1.5 \mathrm{~mm}$.
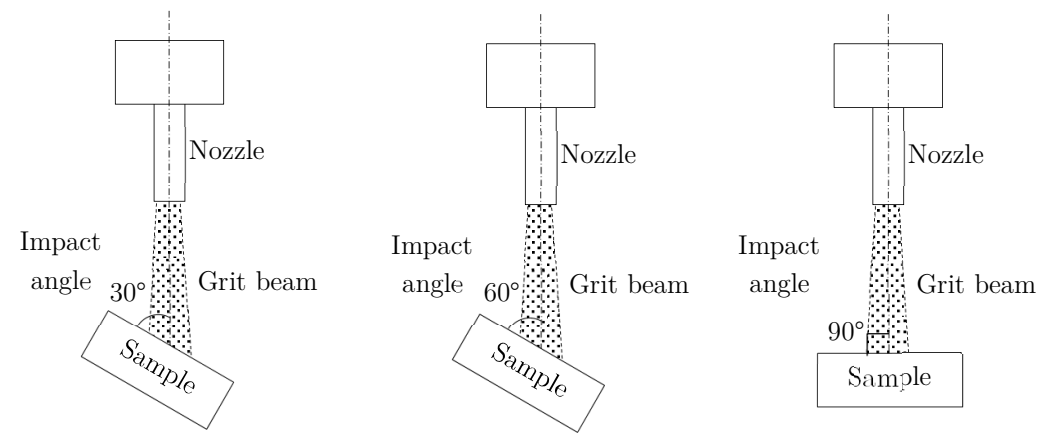

Fig. 2. Schematic representation of the erosion wear test carried out at three different angles. 
Before testing the HVOF deposited samples were cleaned in an acetone ultrasonic bath and mass recorded to a precision of $0.01 \mathrm{mg}$. The coated specimens were then eroded using Alumina particles of average size $50 \mu \mathrm{m}$ (Fig. 3) as the erodent of choice. The tests were conducted for a duration of 10 minutes where the erodent was fed at $5 \mathrm{~g} / \mathrm{min}$ at a velocity of $40 \mathrm{~m} / \mathrm{s}$. As shown in Fig. 3, the alumina erodent particles were found to have a flaky and angular morphology. The distance between the erosion jet nozzle and the coated surface were kept at a constant $10 \mathrm{~mm}$ for all the tests.

An erodent impact angle of $90^{\circ}$ was selected to simulate the erosion behavior in power plants due to fly ash impact which normally occurs at a $90^{\circ}$ impact angle. Following the erodent exposure of the coated surface, the test specimens was cleaned again in an acetone bath and the mass loss compared. Two identical tests under similar conditions were carried to quantify repeatability and the average values analysed. Finally, following the initial assessment and identifying the optimum process parameters, the erosion tests are carried out again on the optimum coated surface at impact angles of $30^{\circ}, 60^{\circ}$, and $90^{\circ}$. The rate of erosion $\left(E_{r}\right)$ can then be expressed using Eqn. (1).

$$
E_{r}=\frac{W_{s}}{W_{e r}}
$$

where $W_{s}$ is the difference in the mass of the erodent sample before and after the erosion test and $W_{e r}$ is a product of the erodent feed rate and test duration.

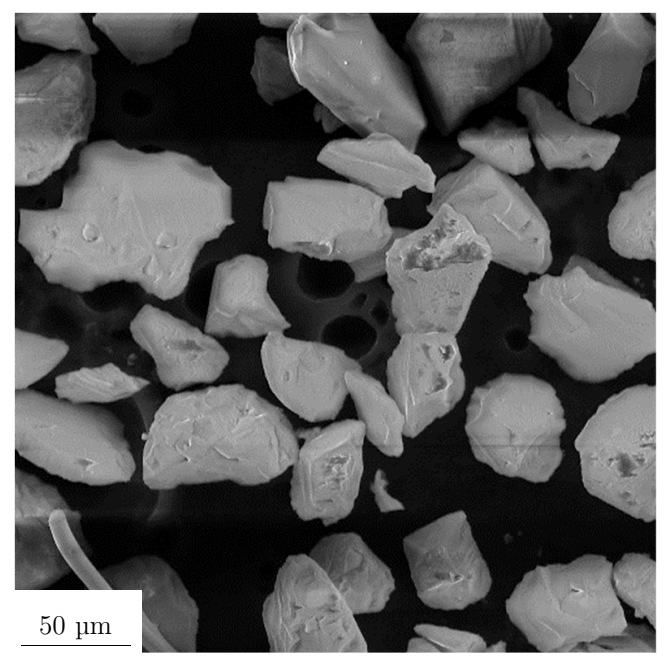

Fig. 3. Alumina erodent used for the erosion wear test on the $\mathrm{HVOF} \mathrm{NiCrSiB}-\mathrm{Al}_{2} \mathrm{O}_{3}$ coating.

\subsection{Characterisation of the optimised coating}

Once the optimum process parameters were identified for $\mathrm{HVOF}$ deposition of $\mathrm{NiCrSiB}-\mathrm{Al}_{2} \mathrm{O}_{3}$ on AISI304 substrate using the Taguchi DoE. An optimum coating cycle was performed and the microstructure [51], porosity [52], microhardness, and surface roughness [53] were characterised. The 
microstructure was studied using an Olympus BX51M optical microscope and Carl Zeiss Evo18 Scanning Electron Microscope (SEM). The SEM also featured an Energy Dispersive Spectroscopy (EDS) from Bruker that allowed the identification of elemental composition and their relative proportions. Furthermore, the feedstock and coating were examined using a Regaku X-Ray Diffractometer (XRD) at room temperature using $\mathrm{CuK} \alpha(\lambda=1.5406 \AA)$ as the radiation source at $40 \mathrm{kV}$. The scanning was carried out while the angle was varied from $10-80^{\circ}$ at a step of $0.02^{\circ}$ holding at a time of $5 \mathrm{~s}$ per step.

The porosity of the NiCrSiB- $\mathrm{Al}_{2} \mathrm{O}_{3}$ deposition was evaluated from the cross-sectional optical microscopy results. The proprietary image analysing software was used for this purpose and resulting porosity is characterised as an average of 10 measurements on the unetched coating. In addition, the microhardness and the surface roughness of the coatings were evaluated using a Wilson diamond indenter hardness tester and stylus type surface roughness tester respectively. The hardness tester featured a built-in camera and applied a load of $300 \mathrm{~g}$ with a hold-cycle of $15 \mathrm{~s}$. The results obtained from ten measurements at different locations were averaged to obtain the microhardness of the coated surface. For the surface roughness measurement, a sampling length of $5 \mathrm{~mm}$ was considered and an average of ten measurements attributed.

\section{Results and Discussions}

\subsection{Process variables and order of influence}

HVOF deposition of $\mathrm{NiCrSiB}-\mathrm{Al}_{2} \mathrm{O}_{3}$ is a complex process and the quality of coating is influenced by a number of process parameters. The variables considered in this study are as shown in Table 3, where $Q_{\text {oxy }}(\mathrm{A}), Q_{\text {fuel }}(\mathrm{B}), \dot{m}_{\text {feed }}(\mathrm{C})$ and $D_{\text {sof }}(\mathrm{D})$ are the flow rate of oxygen, fuel, feed rate of the powder and the standoff distance. The optimum values of these four parameters are critical in achieving the best coating and needs powder material dependent optimisation. This is because of the powder particles leaving the nozzle experience high velocity in combination with rigorous heating causing evaporation, dissolution, and phase transformations which are all highly dependent on the powder composition. This makes the control and optimisation of the HVOF process both crucial and challenging. While different methods can be adopted for the analysis and optimisation of the material dependent HVOF process parameters, a Taguchi based DoE is considered in this study. Using the Taguchi method allows reducing the test matrix at the same time enabling to study the relative importance between variables sufficiently. Accordingly, the experimental results are transformed into a signal-to-noise $(\mathrm{S} / \mathrm{N})$ ratio represented as shown in Eqn. (2):

$$
\eta=-10 \log \left[\frac{1}{n} \sum_{i=1}^{n} E W L_{i}^{2}\right]
$$


Where $n$ and $E W L_{i}$ represents the number of experimental observations and the Erosion Wear Loss (EWL) of the $i^{t h}$ observation respectively. However, the analysis $\eta$ requires identification of one of the three quality characteristics; $(i)$ the smaller-the-better, $($ ii) the nominal-the-best, and (iii) the larger-the-better. Consequently, category $(i)$ the smaller-the-better performance characteristics is considered to study the EWL and to identify the optimum HVOF process conditions [20].

Table 4 Erosion wear loss and associated signal-to-noise ratio for the experimental runs.

\begin{tabular}{ccccccc}
\hline Experiment & $\begin{array}{c}\boldsymbol{Q}_{\boldsymbol{o x y} \boldsymbol{y}}(\mathrm{A}) \\
(\text { lpm })\end{array}$ & $\begin{array}{c}\boldsymbol{Q}_{\boldsymbol{f u e l}}(\mathrm{B}) \\
(\text { lpm })\end{array}$ & $\begin{array}{c}\dot{\boldsymbol{m}}_{\text {feed }}(\mathrm{C}) \\
(\mathrm{g} / \mathrm{min})\end{array}$ & $\begin{array}{c}\boldsymbol{D}_{\text {sof }}(\mathrm{D}) \\
(\mathrm{mm})\end{array}$ & $\begin{array}{c}\boldsymbol{E} \boldsymbol{W} \boldsymbol{L}_{\boldsymbol{i}} \\
(g)\end{array}$ & S/N ratio \\
\hline 1 & 220 & 55 & 28 & 150 & 0.01506 & 36.4435 \\
2 & 220 & 60 & 32 & 200 & 0.01701 & 35.3859 \\
3 & 220 & 65 & 36 & 250 & 0.01529 & 36.3119 \\
4 & 240 & 55 & 32 & 250 & 0.01490 & 36.5363 \\
5 & 240 & 60 & 36 & 150 & 0.01804 & 34.8753 \\
6 & 240 & 65 & 28 & 200 & 0.01269 & 37.9308 \\
7 & 260 & 55 & 36 & 200 & 0.01733 & 35.2240 \\
8 & 260 & 60 & 28 & 250 & 0.01015 & 39.8707 \\
9 & 260 & 65 & 32 & 150 & 0.01435 & 36.8630 \\
\hline
\end{tabular}

Table 4 shows the $\mathrm{S} / \mathrm{N}$ ratio and the associated parametric values for the nine experimental runs considered. Evaluating the results, it is evident that the powder feed rate $\left(\dot{m}_{\text {feed }}\right)$ shows the largest difference $(2.61 \mathrm{~dB})$ between the values of all three configurations as shown in Table 5 . Based on Taguchi prediction model, a larger difference between the values of the signal-to-noise ratio indicates the most influential factor. Consequently, in the order of significance, the process parameters affecting the EWL can be classified as $\dot{m}_{\text {feed }}>D_{\text {sof }}>Q_{\text {oxy }}>Q_{\text {fuel }}$. Based on the analysis presented in Table 5 and Fig. 4, for minimum EWL of $\mathrm{NiCrSiB}-\mathrm{Al}_{2} \mathrm{O}_{3}$ coating, the optimal process parameters required for the HVOF process are $Q_{\text {oxy }}=260 \mathrm{lpm}, Q_{\text {fuel }}=65 \mathrm{lpm}, \dot{\mathrm{m}}_{\text {feed }}=28 \mathrm{~g} / \mathrm{min}$ and $D_{\text {sof }}=250 \mathrm{~mm}$.

Table 5 Mean signal-to-noise response for erosion wear loss under the three categories.

\begin{tabular}{cccccc}
\hline \multirow{2}{*}{ Parameter } & \multicolumn{4}{c}{ Mean S/N ratio } & \multirow{2}{*}{ Rank } \\
\cline { 2 - 5 } & Config. 1 & Config. 2 & Config. 3 & Max-Min & \\
\hline$Q_{\text {oxy }}$ (A) & 36.05 & 36.45 & 37.32 & 1.27 & 3 \\
$Q_{\text {fuel }}$ (B) & 36.07 & 36.71 & 37.04 & 0.97 & 4 \\
$\dot{m}_{\text {feed }}(\mathrm{C})$ & 38.08 & 36.26 & 35.47 & 2.61 & 1 \\
$D_{\text {sof }}$ (D) & 36.06 & 36.18 & 37.57 & 1.51 & 2 \\
\hline
\end{tabular}




\subsection{Influence of process parameters on erosion wear loss}

Fig. 4a shows that when the flow rate of oxygen $\left(Q_{o x y}\right)$ increases, the EWL decreases. This can be attributed to the influence of $Q_{o x y}$ on the combustion reaction that is taking place. Reduced oxygen levels cause inadequate combustion lowering the temperature which leads to incomplete melting of the NiCrSiB- $\mathrm{Al}_{2} \mathrm{O}_{3}$ particles. This increases not only the porosity but also the EWL of the coating. Consequently, a higher $Q_{o x y}$ is preferable to improve the overall quality and erosion wear loss of the coating.

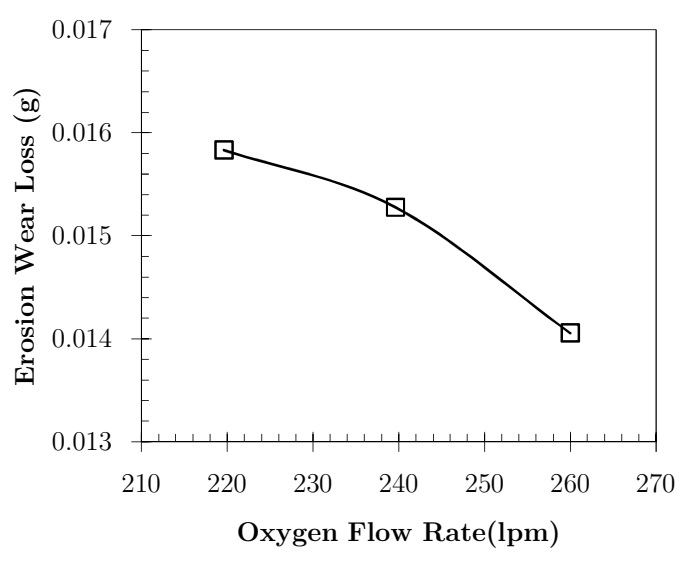

(a)

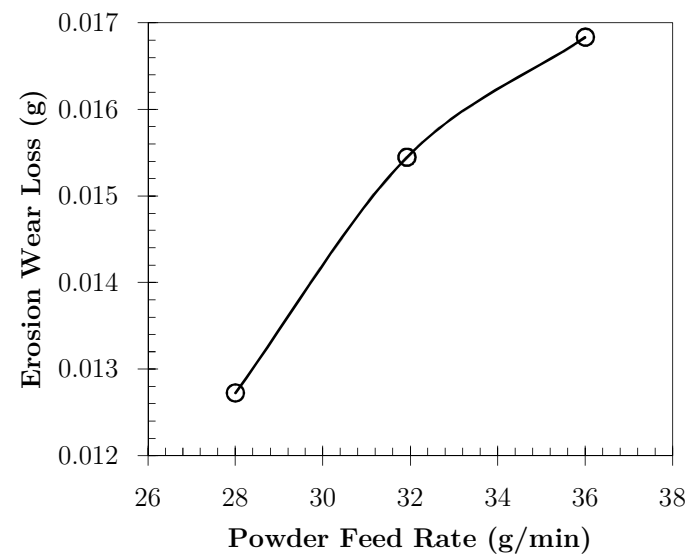

(c)

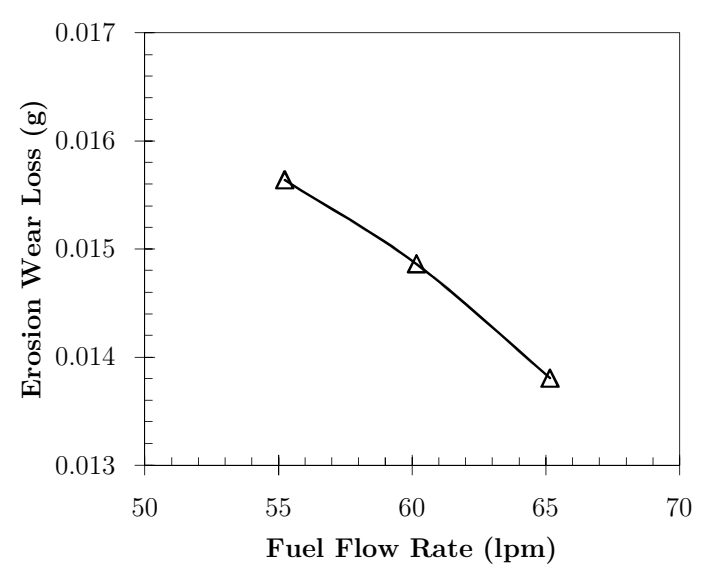

(b)

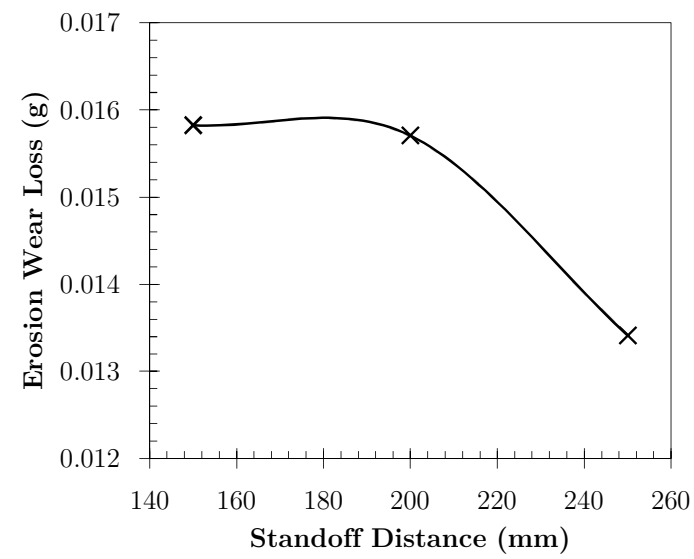

(d)

Fig. 4. Influence of $\mathrm{HVOF}$ process parameters considered on the erosion wear loss of $\mathrm{NiCrSiB}-\mathrm{Al}_{2} \mathrm{O}_{3}$ composite coating where (a) shows $Q_{o x y}$, (b) $Q_{f u e l}$, (c) $\dot{m}_{\text {feed }}$ and (d) $D_{\text {sof }}$.

However, increasing $Q_{\text {oxy }}$ further, decreases the temperature due to the excess oxygen acting as cooling gas [54] due to the relatively shorter time the $\mathrm{NiCrSiB}-\mathrm{Al}_{2} \mathrm{O}_{3}$ powder are exposed to flame. Consequently, the optimum $Q_{o x y}$ was found to be $260 \mathrm{lpm}$ at an EWL of $0.01365 \mathrm{~g}$. When it comes to the influence of fuel flow rate $\left(Q_{f u e l}\right)$, the EWL was found to decreases with an increase in $Q_{f u e l}$ 
as shown in Fig. 4b. Consequently, the lowest EWL was observed at a $Q_{\text {fuel }}$ of $65 \mathrm{lpm}$. High $Q_{\text {fuel }}$, increases the temperature thereby melting the $\mathrm{NiCrSiB}-\mathrm{Al}_{2} \mathrm{O}_{3}$ favourably affecting both the flow and compaction of the deposition. This can be related to the work of Murugan et al. [55], where WC$10 \mathrm{Co}-4 \mathrm{Cr}$ also showed similar interaction to the changes in the HVOF fuel flow rate.

The feed rate of $\mathrm{NiCrSiB}-\mathrm{Al}_{2} \mathrm{O}_{3}\left(\dot{m}_{\text {feed }}\right)$ was found to have a significant effect on the EWL as shown in Fig. 4c. Erosion wear loss of the resulting $\mathrm{NiCrSiB}-\mathrm{Al}_{2} \mathrm{O}_{3}$ coating increased drastically with the increase in $\dot{m}_{\text {feed }}$. Incomplete melting of $\mathrm{NiCrSiB}-\mathrm{Al}_{2} \mathrm{O}_{3}$ was observed on increasing $\dot{m}_{\text {feed }}$ from 0.01263 to $0.01689 \mathrm{~g}(\sim 29 \%)$. Unevenly and insufficiently melted coating particles are known to decrease flattening as the molten particles hit the substrate. This in turn decreases the packing density and increases the porosity of the resulting deposition layer. However, when $\dot{m}_{\text {feed }}$ was lowered, the particles achieved sufficient melting to produce a fully dense coating. This is primarily because of the high packing density facilitated by the adequately molten particles subsequently leading to both low EWL and porosity [36]. Accordingly, the lowest EWL was observed at $\dot{m}_{\text {feed }}$ of $28 \mathrm{~g} / \mathrm{min}$.

Furthermore, the distance between the HVOF nozzle and the substrate $\left(D_{\text {sof }}\right)$ was also found to affect the EWL as shown in Fig. 4d. At longer $D_{\text {sof }}$, the erosion wear loss improved by approximately $16 \%$ (from 0.01582 to $0.01345 \mathrm{~g}$ ) in comparison to the shortest tested. This is because at longer $D_{\text {sof }}$, the particles have a longer distance of travel before hitting the substrate. During this time, the interaction of the $\mathrm{NiCrSiB}-\mathrm{Al}_{2} \mathrm{O}_{3}$ particles with the HVOF flame increases leading to an improved melt-pool resulting in higher particle packing density and subsequently lowers porosity. The findings can be further substantiated from the works of Sobolev et al. [56] and Planche et al. [57] where a significant influence of standoff distance on the temperature and velocity of the particles were reported. Accordingly, increasing $D_{\text {sof }}$ increases the erosion resistance with a distance of $250 \mathrm{~mm}$ being the most appropriate to reduce EWL of $\mathrm{NiCrSiB}-\mathrm{Al}_{2} \mathrm{O}_{3}$ coating on an AISI304 substrate.

After studying the influence of the independent process variables on the EWL of the deposition, it was essential to identify the interaction between the process parameters to deduce an optimum solution without undesirable outcomes. Accordingly, Fig. 5 presents the interaction between the $\mathrm{HVOF}$ process parameters on the EWL of $\mathrm{NiCrSiB}-\mathrm{Al}_{2} \mathrm{O}_{3}$ deposition. Fig. 5 a shows more or less a linear trend between the interaction of $Q_{o x y}$ and $Q_{f u e l}$, where an increase in both of the parameters resulted in reducing the EWL. The highest values for $Q_{o x y}$ and $Q_{f u e l}$ resulted in the lowest EWL of $0.0135 \mathrm{~g}$. The opposite was true with the highest wear loss range of $0.0165 \mathrm{~g}$ at the lowest $Q_{o x y}$ and $Q_{\text {fuel }}$ setting. 


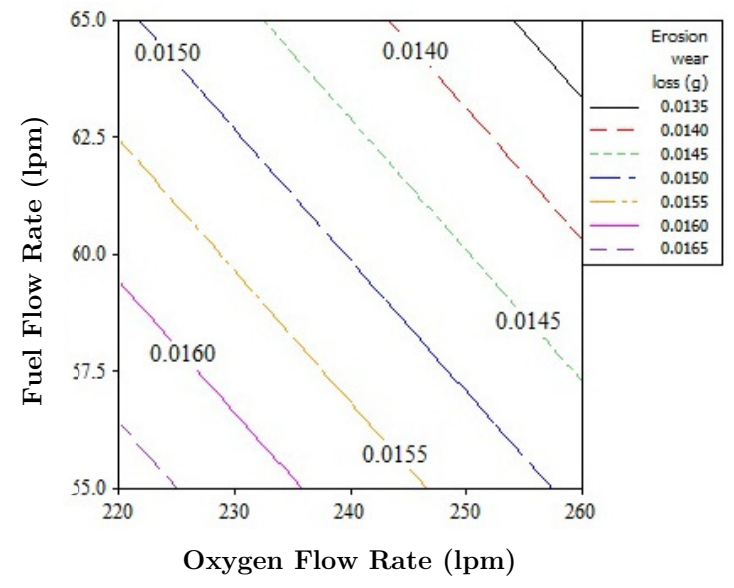

(a)

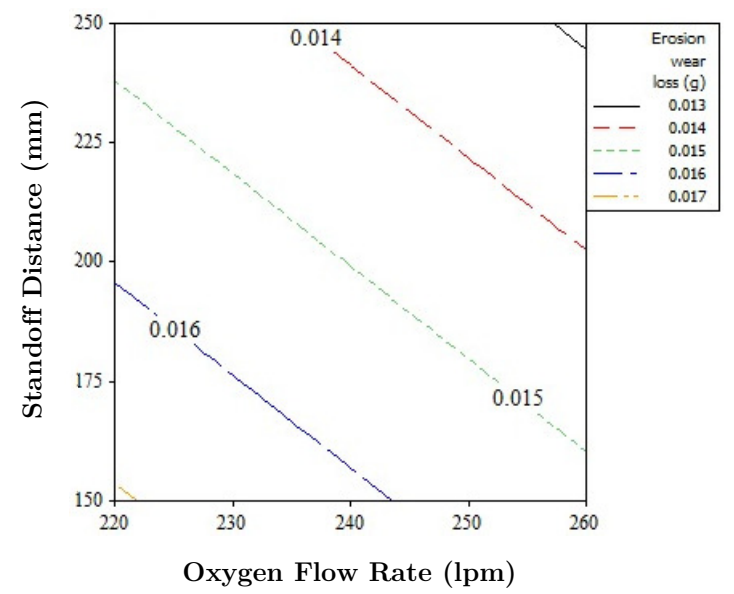

(c)

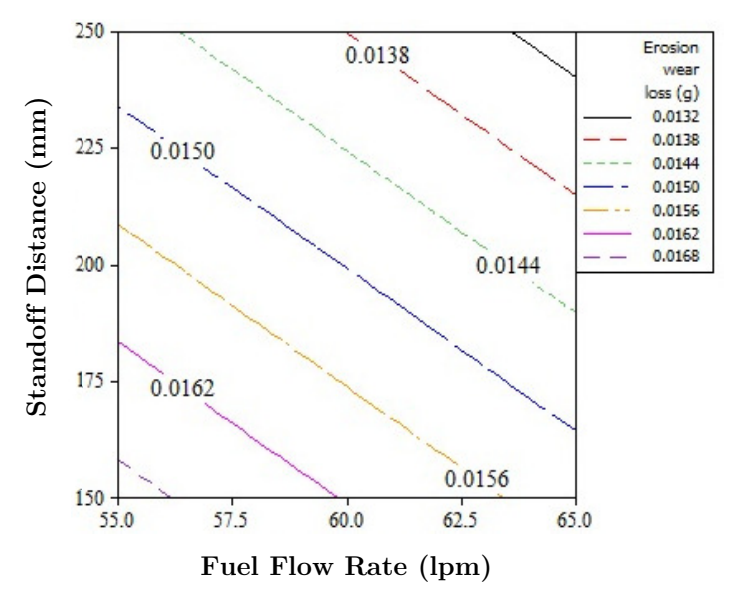

(e)

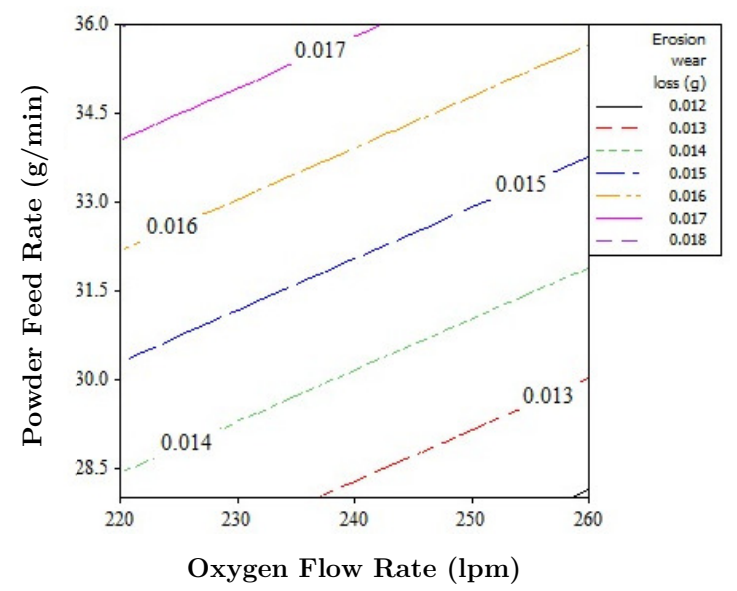

(b)

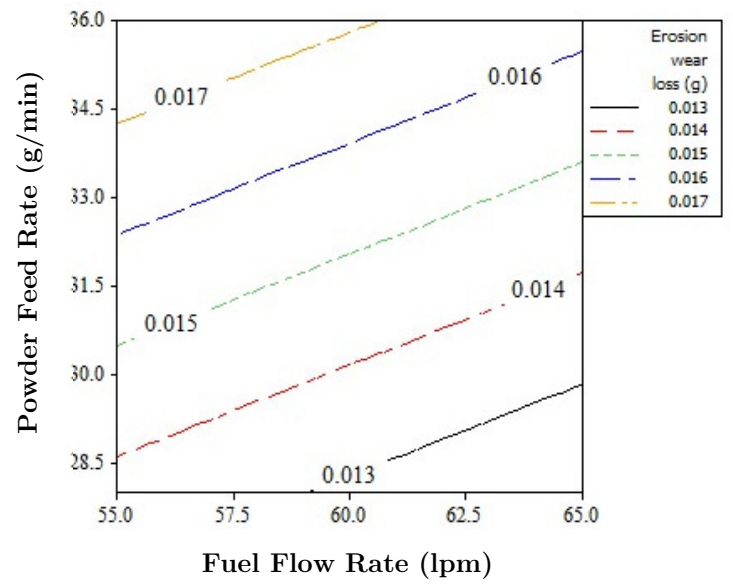

(d)

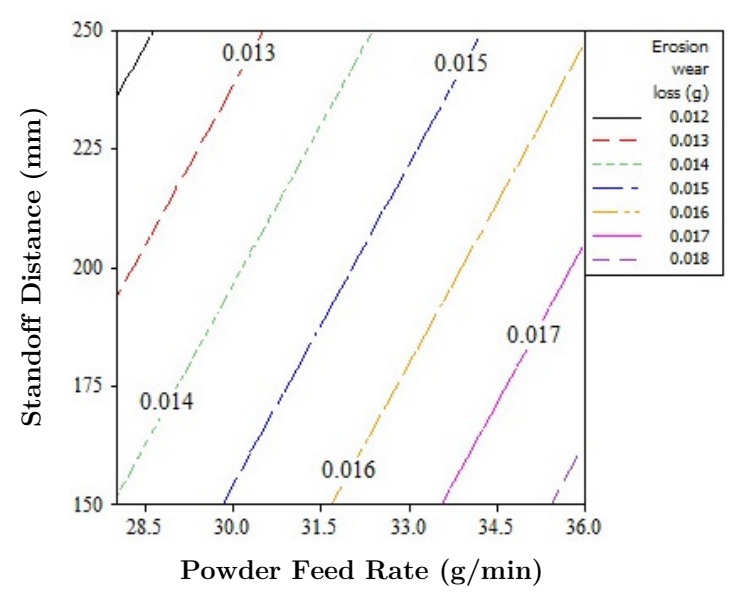

(f)

Fig. 5. Effect of process parameter interaction on the erosion wear loss of $\mathrm{NiCrSiB}-\mathrm{Al}_{2} \mathrm{O}_{3}$ deposition where (a) shows interaction between $Q_{o x y}$ and $Q_{\text {fuel }}$ (b) $Q_{o x y}$ and $\dot{m}_{f e e d}$, (c) $Q_{o x y}$ and $D_{\text {sof }}$, (d) $Q_{\text {fuel }}$ and $\dot{m}_{f e e d}$ (e) $Q_{f u e l}$ and $D_{\text {sof }}$ and (f) $\dot{m}_{\text {feed }}$ and $D_{\text {sof }}$. 
Evaluating the interaction between $Q_{o x y}$ and $\dot{m}_{f e e d}$ as shown in Fig. 5b, a high EWL of $>0.017 \mathrm{~g}$ was observed at low $Q_{o x y}$ and high $\dot{m}_{\text {feed }}$. For the inverse case of high $Q_{o x y}$ and low $\dot{\mathrm{m}}_{\text {feed }}$ the wear loss was the lowest at $0.013 \mathrm{~g}$. This shows that while increasing $Q_{o x y}$, reducing $\dot{\mathrm{m}}_{\text {feed }}$ will result in a $\mathrm{NiCrSiB}-\mathrm{Al}_{2} \mathrm{O}_{3}$ deposition with high erosion resistance.

Combining this with the interaction of $Q_{o x y}$ with $\mathrm{D}_{\text {sof }}$ as shown in Fig. 5c, a larger value of both the parameters $\left(Q_{o x y}=260 \mathrm{lpm}\right.$ with $\left.D_{\text {sof }}=250 \mathrm{~mm}\right)$ was found to be favourable to obtain the lowest EWL of $0.013 \mathrm{~g}$. When it comes to the interaction between $Q_{\text {fuel }}$ and $\dot{\mathrm{m}}_{\text {feed }}$ (Fig. $5 \mathrm{~d}$ ), the EWL was high $(<0.017 \mathrm{~g})$ at low $Q_{\text {fuel }}$ and high $\dot{m}_{\text {feed }}$. This combination clearly results in incomplete melting of the $\mathrm{NiCrSiB}-\mathrm{Al}_{2} \mathrm{O}_{3}$ powders leading to poor erosion resistance. Nevertheless, at low $\dot{\mathrm{m}}_{\text {feed }}$, the EWL was also found to be lower $(<0.013 \mathrm{~g})$ between $Q_{\text {fuel }}$ of 60 to $65 \mathrm{lpm}$.

Fig. 5e shows higher EWL $(0.0168 \mathrm{~g})$ for a 55 to $60 \mathrm{lpm}$ range of $Q_{\text {fuel }}$ at a low $D_{\text {sof }}$. However, the opposite was true $\left(<0.0132 \mathrm{~g}\right.$ EWL) for a 60 to $65 \mathrm{lpm}$ range of $Q_{\text {fuel }}$ at $D_{\text {sof }}$ of 225 to 250 mm. In comparison, the wear loss was high $(>0.018 \mathrm{~g})$ for a 34 to $36 \mathrm{~g} / \mathrm{min} \dot{m}_{\text {feed }}$ at $D_{\text {sof }}$ of 150 to $200 \mathrm{~mm}$ as shown in Fig. 5f. In addition, a low $\dot{\mathrm{m}}_{\text {feed }}$ resulted in a better EWL $(<0.012 \mathrm{~g})$ at a $D_{\text {sof }}$ between 230 and $250 \mathrm{~mm}$. Overall, the results shows that there is a significant interaction between the HVOF process parameters considered, consequently, the representation of their significance is crucial to obtain $\mathrm{NiCrSiB}-\mathrm{Al}_{2} \mathrm{O}_{3}$ coating with the highest erosion resistance.

\subsection{Prediction model for optimum coating}

After establishing the interaction between the HVOF process parameters and the erosion resistance of $\mathrm{NiCrSiB}-\mathrm{Al}_{2} \mathrm{O}_{3}$ deposition, the analysis of variance (ANOVA) technique was used to model the significance of each of the process parameter on the EWL. ANOVA was carried out by dividing the total variability of signal-to-noise $(\mathrm{S} / \mathrm{N})$ ratios into contributions by each process parameter and the error. Eqns. (3) and (4) were used to find the total sum of the squared deviations $(S S)_{T}$ and the sum of squared deviation due to each process parameter $(S S)_{P}$ :

$$
\begin{gathered}
(S S)_{T}=\sum_{i=1}^{m} \eta_{i}^{2}-m \eta_{m}^{2} \\
(S S)_{P}=\sum_{j=1}^{t} \frac{\left(s \eta_{j}\right)^{2}}{t}-\frac{1}{m}\left[\sum_{i=1}^{m} \eta_{i}\right]^{2}
\end{gathered}
$$

Where $m$ is the number of experiments in an orthogonal array, $\eta_{i}$ the mean $\mathrm{S} / \mathrm{N}$ ratio for the $i^{t h}$ experiment, $\eta_{m}$ the total mean of $\mathrm{S} / \mathrm{N}$ ratio, $j$ the level number of the process parameter $p, t$ the repetition of each level of the parameter $p$, and $s \eta_{j}$ the sum of the $\mathrm{S} / \mathrm{N}$ ratio involving the parameter 
$p$ at level $j$. The sum of squared deviation due to error $(S S)_{e}$ was calculated from the difference of the total sum of the squared deviations $(S S)_{T}$ and the sum of the squared deviation due to each process parameter as shown in Eqn. (5):

$$
(S S)_{e}=(S S)_{T}-\sum_{(p=1)}^{3}(S S)_{p}
$$

From $(S S)_{p}$ and $(S S)_{e}$, the variance of process parameters $\left(V_{p}\right)$ and error $\left(V_{e}\right)$ were calculated using Eqns. (6) and (7):

$$
\begin{gathered}
V_{p}=\frac{(S S)_{p}}{(d f)_{p}} \\
V_{e}=\frac{(S S)_{e}}{(d f)_{e}}
\end{gathered}
$$

where $(d f)_{p}$ and $(d f)_{e}$ are the respective degrees of freedom of the process parameter and the error given by $(t-1)$. The corrected sum of squared $(\dot{S})_{p}$ was calculated using Eqn. (8):

$$
(\hat{S})_{p}=(S S)_{p}-(d f)_{p} V_{e}
$$

Finally, the percentage contribution $\rho$ of each process parameter on the EWL of the coating was evaluated using Eqn. (9):

$$
\rho=\frac{(\hat{S})_{p}}{(S S)_{T}}
$$

Table 6 shows the ANOVA results of the EWL for the deposition linking the process parameters at a confidence of $92.6 \%$ (R-Sq). Accordingly, the results show that $\dot{m}_{\text {feed }}$ has the highest contribution $(\sim 55 \%)$ followed by $D_{\text {sof }}(\sim 22 \%)$ influence towards reducing the EWL and resulting in an optimum solution. The $Q_{f u e l}$ was found to be the least influential followed by $Q_{o x y}$ with contributions limited to 7 and $16 \%$ respectively. Consequently, the F-ratio value of $Q_{\text {fuel }}$ as the least significant factor becomes negligible.

Table 6 ANOVA results of the influence of process parameters on the erosion wear loss of $\mathrm{NiCrSiB}_{-} \mathrm{Al}_{2} \mathrm{O}_{3}$ deposition.

\begin{tabular}{lccccc}
\hline \multicolumn{1}{c}{ Parameters } & $\begin{array}{c}\text { Degree of } \\
\text { freedom (f) }\end{array}$ & $\begin{array}{c}\text { Sum of } \\
\text { squares (S) }\end{array}$ & $\begin{array}{c}\text { Variance } \\
(\mathbf{V})\end{array}$ & F-ratio (F) & $\begin{array}{c}\text { Contribution } \\
(\%)\end{array}$ \\
\hline$Q_{\text {oxy }}(\mathrm{A})$ & 2 & 3.2208 & 1.6104 & 2.2151 & 16.3715 \\
$\dot{m}_{\text {feed }}(\mathrm{C})$ & 2 & 10.7571 & 5.3785 & 7.3984 & 54.6795 \\
$D_{\text {sof }}(\mathrm{D})$ & 2 & 4.2412 & 2.1206 & 2.9169 & 21.5583 \\
$Q_{\text {fuel }}$ (B) (error) & 2 & 1.4540 & 0.7270 & - & 7.3908 \\
Total & 8 & 19.6730 & & & 100.0000 \\
\hline
\end{tabular}


Based on the ANOVA results, a prediction model for the EWL combining the four process parameters within the specified levels were derived. The regression analysis used for the prediction model showed a significance of 93.1\% (R-Sq) resulting in Eqn. (10):

$$
E W L=0.0237-0.000046 A-0.000165 B+0.000532 C-0.000024 D
$$

Where EWL is the erosion wear loss of the $\mathrm{NiCrSiB}-\mathrm{Al}_{2} \mathrm{O}_{3}$ coated surface in grams $(\mathrm{g})$ and $\mathrm{A}, \mathrm{B}, \mathrm{C}$, D are $Q_{\text {oxy }}, Q_{\text {fuel }}, \dot{m}_{\text {feed }}$ and $D_{\text {sof }}$ respectively; referring to the four process parameters associated with the HVOF process.

\subsection{Experimental validation of the prediction model}

Experimental validation is performed to verify the predicted result using the proposed model in Eqn. (3). Based on the parametric analysis (Fig. 4 and 5) and the resulting EWL, optimum level of parameters was identified. This resulted in parameter model that can be presented as A3B3C1D3 which refers to the level of parametric values that result in the highest erosion resistance (lowest EWL). The results from Table 7 shows that using optimum parametric values, both the prediction model and the experimental results resulted in a minimum EWL. Furthermore, a $4.89 \%$ difference between experimental and predicted results shows a high correlation this validating Eqn. (3).

Table 7 Performance of the prediction model in comparison to experimental test results.

\begin{tabular}{lccc}
\hline \multirow{2}{*}{ Item } & \multicolumn{2}{c}{ Optimal process parameters } & \multirow{2}{*}{ Error (\%) } \\
\cline { 2 - 3 } & Predicted & Experimental & \\
\hline Level & A3B3C1D3 & A3B3C1D3 & \multirow{2}{*}{4.89} \\
EWL $(\mathrm{g})$ & 0.00991 & 0.01042 & \\
\hline
\end{tabular}

\subsection{Characterisation of the optimum coating}

A comparison of the XRD profiles between the NiCrSiB- $\mathrm{Al}_{2} \mathrm{O}_{3}$ powder and optimum HVOF deposition is shown in Fig. 6a and 6b. The results from the coating (Fig. 6b) indicate a high intensity of Nickel $(\mathrm{Ni})$ and low-levels of Nickel oxide $(\mathrm{NiO})$. The latter can be the result of oxidation of the $\mathrm{NiCrSiB}-\mathrm{Al}_{2} \mathrm{O}_{3}$ powder during $\mathrm{HVOF}$ thermal spraying. Furthermore, the variation in peak width, despite small point towards possible amorphisation during deposition. Similar observation of $\mathrm{NiO}$ was found by Grewal et al. [13] when Ni was combined with $\mathrm{Al}_{2} \mathrm{O}_{3}$ processed using a high velocity flame spray (HVFS) on a steel substrate. 


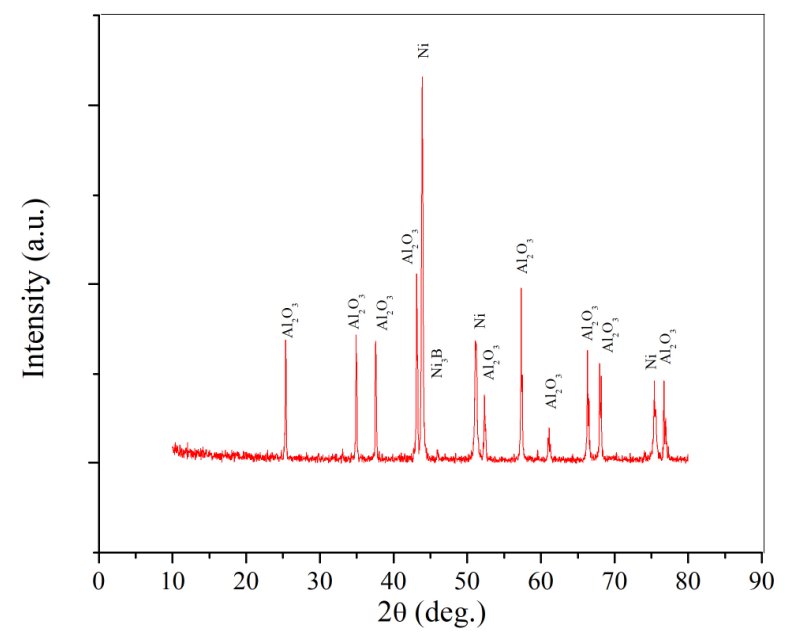

(a)

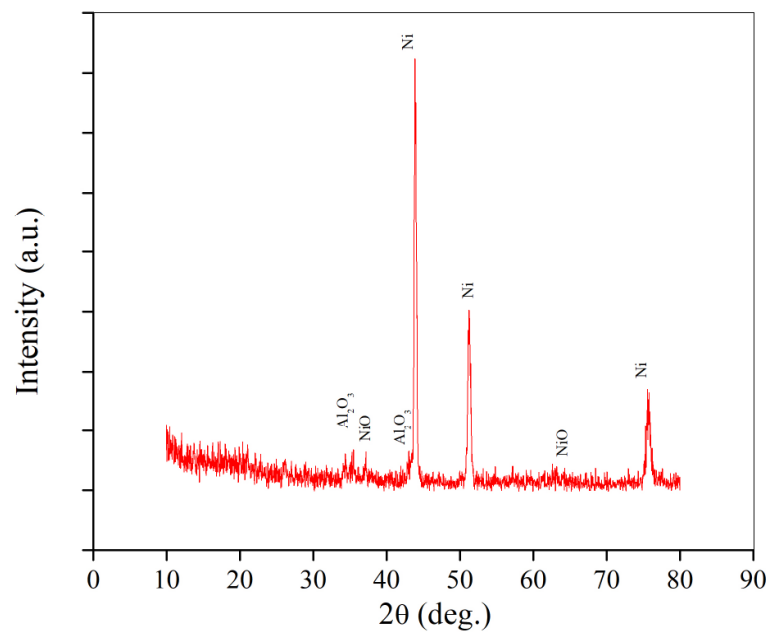

(b)

Fig. 6. X-Ray Diffractometer (XRD) results for (a) $\mathrm{NiCrSiB}-\mathrm{Al}_{2} \mathrm{O}_{3}$ powder and (b) optimum HVOF coating.

The SEM micrographs showing the surface morphology of the coated surface is shown in Fig. 7a. The results show typical splat morphology representative of HVOF Ni-based deposition. Furthermore, a combination of fully, partially and un-melted particles in the form of globules are visible along the surface. In some cases fine fragments of particles can be also observed along the surface often observed in thermal spray coating. Evaluating the cross-sectional micrographs as shown in Fig. 7b, the deposition seems to have a typical laminal structure. In addition, a continuous and defect-free contact between the substrate and the coating can be observed. The interface indicates a typical mechanical anchorage as a result of the HVOF process which seems to be responsible for the interface bonding.

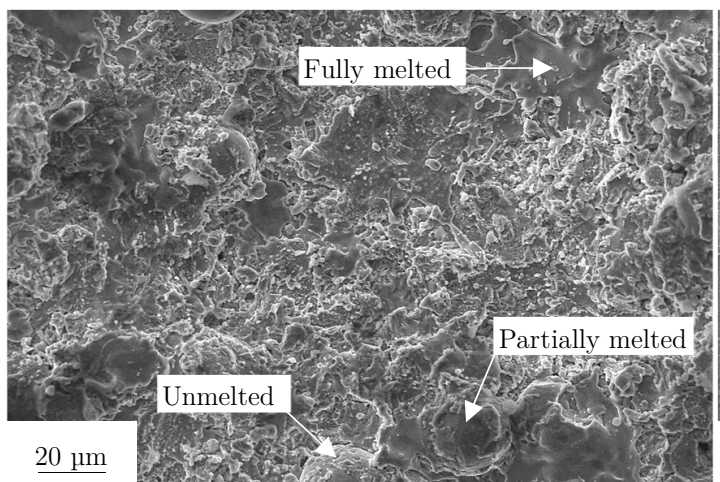

(a)

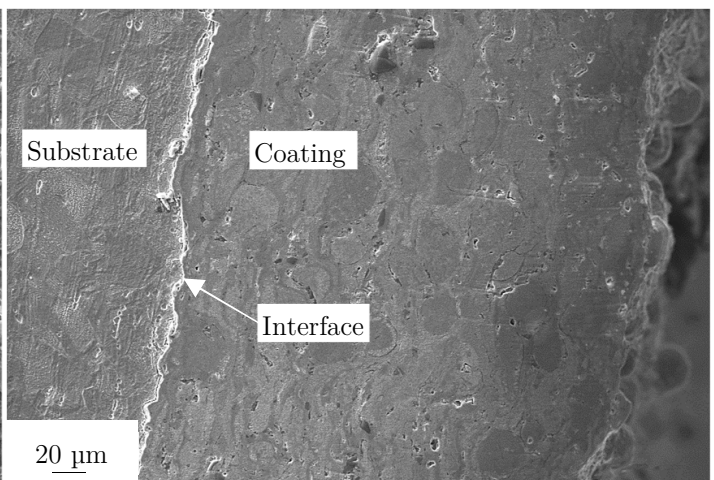

(b)

Fig. 7. Optimised HVOF deposited $\mathrm{NiCrSiB}-\mathrm{Al}_{2} \mathrm{O}_{3}$ coating at $20 \mu \mathrm{m}$ resolution from $\mathrm{SEM}$ showing (a) surface morphology of the coating and (b) cross-section showing the interface between the substrate and coating. 
A cross-sectional metallographic examination using Energy Dispersive Spectroscopy (EDS) was carried out on the polished section shown in Fig. 8a. An elemental mapping across the optimally coated cross-section resulted in Fig. 8b, where the presence of Ni-rich particle embedded in the microstructure can be observed. The coating shows a good level of bonding between the splats with the presence of some micro-voids. It is obvious that the that the splats are nearly homogenously distributed over most of the cross-section. In addition, traces of $\mathrm{Cr}, \mathrm{Al}, \mathrm{O}$, and $\mathrm{Fe}$ can also be seen. The presence of $\mathrm{Fe}$ as shown in Fig. 8c indicates potential diffusion from the substrate towards the deposition, possibly along the splat boundaries.

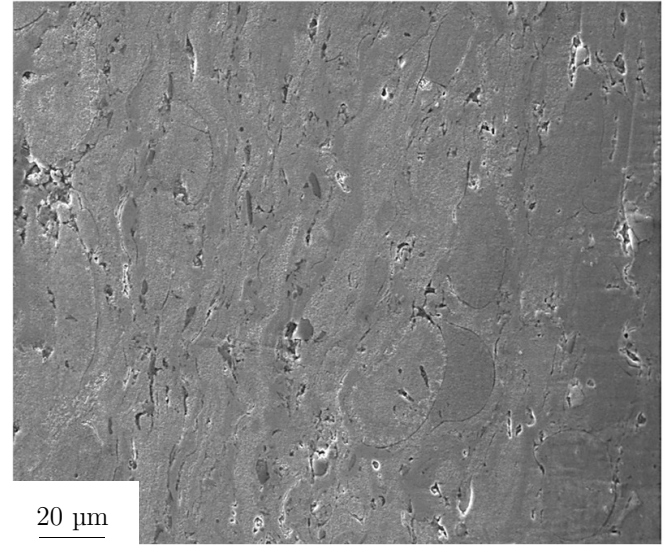

(a)

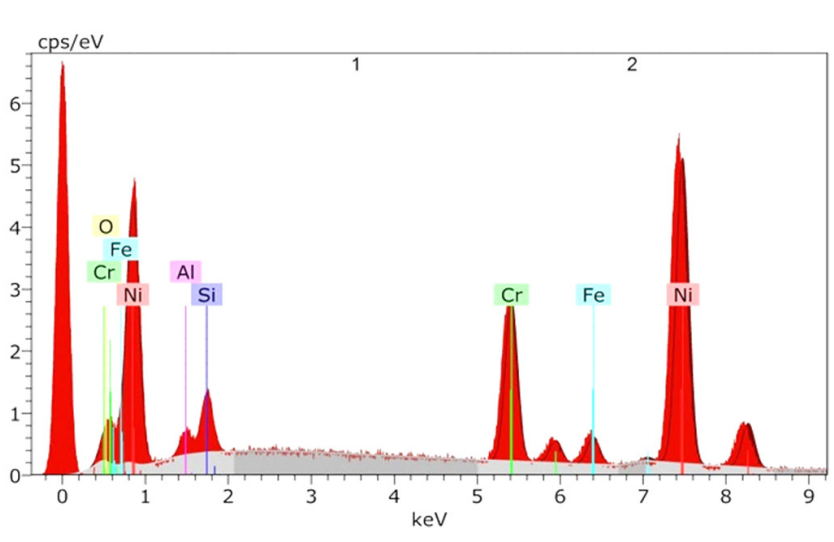

(b)
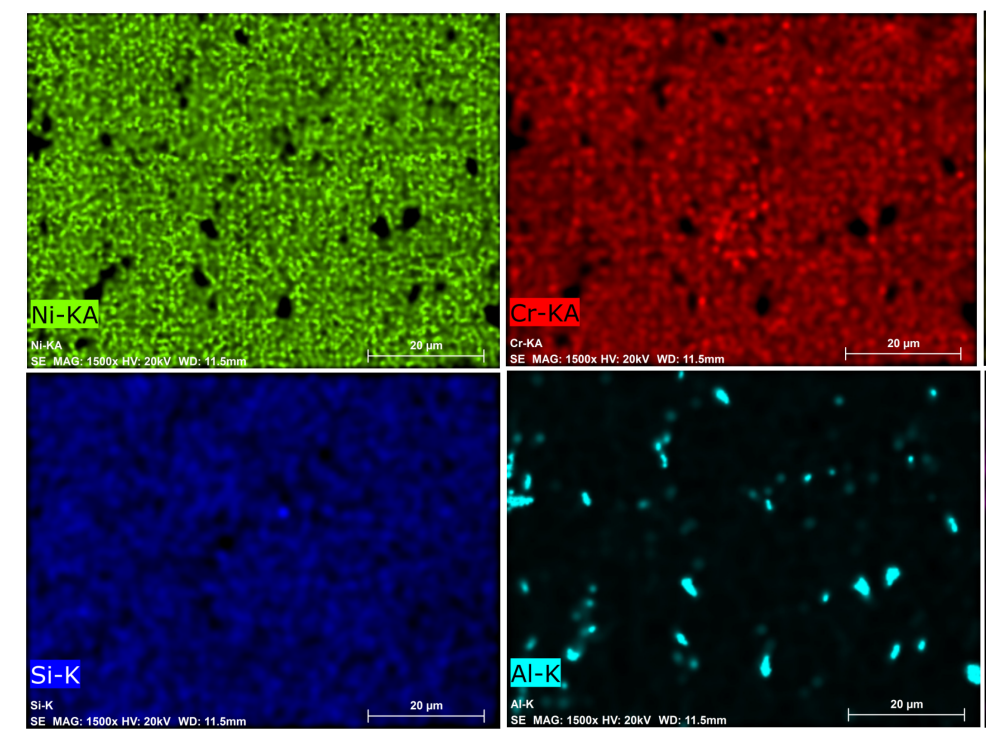

(c)

Fig. 8. Energy Dispersive Spectroscopy analysis of the coating showing (a) cross-section (b) the resulting metallographic spectrum and (c) the area map showing dispersion. 
Evaluating the microhardness, the substrate material AISI304 exhibited an average value of $180 \mathrm{HV}_{0.3}$ before $\mathrm{NiCrSiB}-\mathrm{Al}_{2} \mathrm{O}_{3}$ HVOF deposition. Following the coating, the microhardness adjacent to the deposition interface was found to be $386 \mathrm{HV}_{0.3}$. This is more than a 2 folds increment in comparison to the microhardness of the pre-coated substrate. The spike the microhardness can be attributed to the work-hardening effect of AISI304 as a result of abrader impact while grit blasting and coating particles during HVOF. A similar rise in microhardness was reported by $\mathrm{Hu}$ et al. [58] and Li et al. [59] using cold spraying technique of Ni and Al-based composites.

For the $\mathrm{HVOF}$ coated $\mathrm{NiCrSiB}-\mathrm{Al}_{2} \mathrm{O}_{3}$ region, an average hardness of $843 \mathrm{HV}_{0.3}$, comprising a maximum of $924 \mathrm{HV}_{0.3}$ and minimum of $736 \mathrm{HV}_{0.3}$ respectively. This is a variation of almost $+9 \%$ and $-13.5 \%$ of the average values across the coated surface. While an acceptable case, the variation can be the result of differences phases in the coating region. For example, comparing the measured hardness value of the HVOF coated surface with a plasma spray technique used in previous work [40], a higher hardness was observed for HVOF spray. This can be due to the good cohesive strength and low porosity of the $\mathrm{NiCrSiB}-\mathrm{Al}_{2} \mathrm{O}_{3}$ as a result of the optimal melt-pool contributed by the HVOF technique employed. In terms of surface roughness, the average roughness of the coated surface was found to be $9.3 \mu \mathrm{m}$ at a standard deviation of $2.4 \mu \mathrm{m}$. Furthermore, the porosity was found to be $1.5 \pm 0.4 \%$ consistent with the existing literature on HVOF sprayed alternative coatings $[2,60-62]$.

\subsection{Erosion mechanism of the optimised coating}

The HVOF coated substrates were scrutinised under erosion test featuring impact angles of $30^{\circ}, 60^{\circ}$ and $90^{\circ}$. From the results shown in Fig. 9, the size of the wear-scar can be seen decreasing gradually as the impact angle is increased from $30^{\circ}$ to $90^{\circ}$. Furthermore, a change in scar shape was also observed with elliptical at $30^{\circ}$, circular at $60^{\circ}$ and slightly smaller circle at $90^{\circ}$. The elliptical shape at $30^{\circ}$ can be due to the higher divergence of the erodent zone. Similar observations were observed in solid particle erosion tests carried out on AISI 304, 316 and 420 stainless steel by Laguna-Camacho et al. [63].

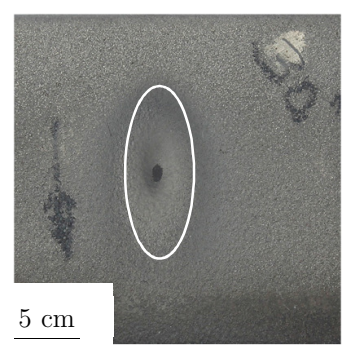

(a)

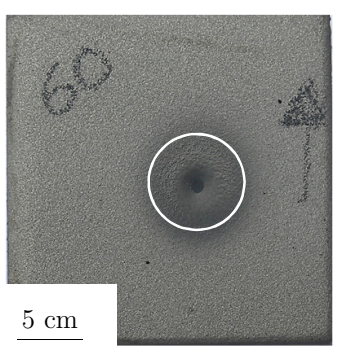

(b)

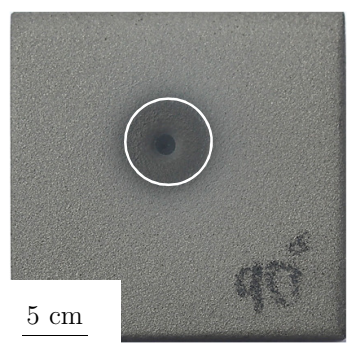

(c)

Fig. 9. HVOF coated $\mathrm{NiCrSiB}-\mathrm{Al}_{2} \mathrm{O}_{3}$ eroded specimens showing impact angle of (a) $30^{\circ}$, (b) $60^{\circ}$ and (c) $90^{\circ}$. 
Further evaluation of the wear area revealed a concentrated central erosion zone, where significant wear can be identified in all the three cases shown in Fig. 9. This was followed by a slightly larger moderate wear zone with a boundary layer featuring negligible wear. The mechanism of EWL at the $\mathrm{NiCrSiB}-\mathrm{Al}_{2} \mathrm{O}_{3}$ deposition whereof both ductile and brittle nature. While the ductile mechanism was responsible for the highest erosion at low impact angles, brittle erosion was responsible for maximum wear at high impact angles. Studies by Bhandari et al. [64] on HVOF coated $\mathrm{Al}_{2} \mathrm{O}_{3}$ and $\mathrm{Al}_{2} \mathrm{O}_{3}-13 \mathrm{TiO}_{2}$ steel substrate was also found to show brittle fracture mechanism and associated erosion when exposed to a slurry erosion exposure. Consequently, the presence of $\mathrm{Al}_{2} \mathrm{O}_{3}$ can be attributed to the brittle erosion mechanism observed.

Looking at the overall influence of erodent impact angle on the erosion wear rate $\left(E_{r}\right)$ of $\mathrm{NiCrSiB}$ $\mathrm{Al}_{2} \mathrm{O}_{3}$ HVOF coated AISI304 substrate as shown in Fig. 10. It is evident that the rate of erosion at an erodent impact stream of $30^{\circ}$ is the highest in comparison to the other angles tested. The difference in erosion resistance at $90^{\circ}$ was almost 1.6 times higher than $30^{\circ}$. This means that while the erosion resistance to compressive wear is higher, shear resistance and hence shear strength of the coating is significantly lower. Accordingly, the $\mathrm{HVOF}$ NiCrSiB- $\mathrm{Al}_{2} \mathrm{O}_{3}$ is capable of absorbing a comparatively large amount of energy as a result of the impinging particles at a $90^{\circ}$ (vertical) impact angle.



Fig. 10. Influence of erodent impact angle on the erosion wear rate of $\mathrm{HVOF} \mathrm{NiCrSiB}-\mathrm{Al}_{2} \mathrm{O}_{3}$ coated AISI304 substrate.

Upon impact by abrasive particles, the high contact stress generates crack points at discontinuities along the coating deposition. This is visible in post-erosion SEM analysis as shown in Fig. 11, where plastic shear deformation has occurred as a result of erodent sliding at $30^{\circ}$ and $60^{\circ}$ impact stream angles. Additionally, the generation of Hertzian contact stresses [65] has developed sub-surface shear stresses that led to the formation of micro-cutting and ploughing as shown in Fig. 11a. The associated erodent impact marks can also be observed as grooves and lips on soft-bonded regions of 
the deposition. These impact marks once formed act as stress raisers and crack initiators degrading the coating through fracture of the displaced material and also adding to the overall discontinuity accelerating subsequent erodent impact.

Comparing the morphologies, a higher number of grooves and plough marks can be seen at an impact angle of $30^{\circ}$ (Fig. 11a) versus $60^{\circ}$ (Fig. 11b). This is due to the higher shear stress induced as a result of the maximum axial offset loading experienced by the low impact angle in comparison to the others tested $\left(60^{\circ}\right.$ and $\left.90^{\circ}\right)$ [58]. In contrast, a perfectly axial $\left(90^{\circ}\right)$ impact resulted in craters as a result of the compressive impact stress of the erodent. This resulted in further strain localisation forming extruded lips surrounding the craters. Though the reason for material extrusion can be the occurrence of the soft bound matrix, the features are representative of ductile erosion. Unlike brittle erosion, ductile erosion shows higher resistance towards crack generation, propagation, and fracture.

Due to the impact energy of the erodent collision at $90^{\circ}$, extensive indentation deformation and dislocations are visible. Highest fracturing and pull of $\mathrm{Al}_{2} \mathrm{O}_{3}$ particle were also observed at $90^{\circ}$ followed by $60^{\circ}$ with relatively minimal occurrence at $60^{\circ}$. It is possible that the accumulation of the dislocations as a result of subsequent erodent impact accelerates the $\mathrm{Al}_{2} \mathrm{O}_{3}$ particle pull-out along the weak-bonding boundaries. Nevertheless, the fracturing of the $\mathrm{Al}_{2} \mathrm{O}_{3}$ particle can be attributed to lateral cracks intersection formed due to the indentation of irregularly shaped alumina erodent on brittle $\mathrm{Al}_{2} \mathrm{O}_{3}$ particles in the deposition.

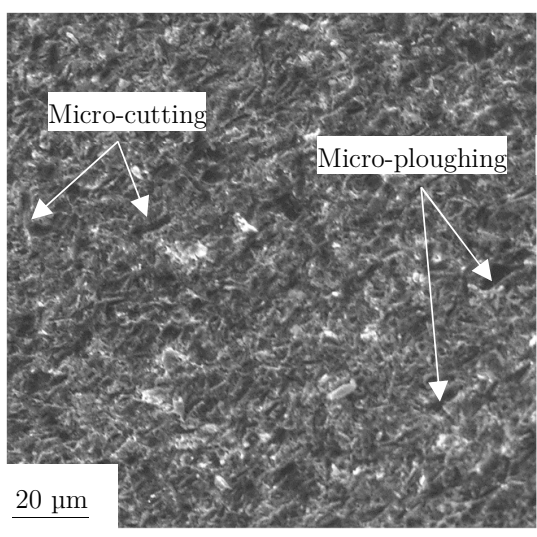

(a)

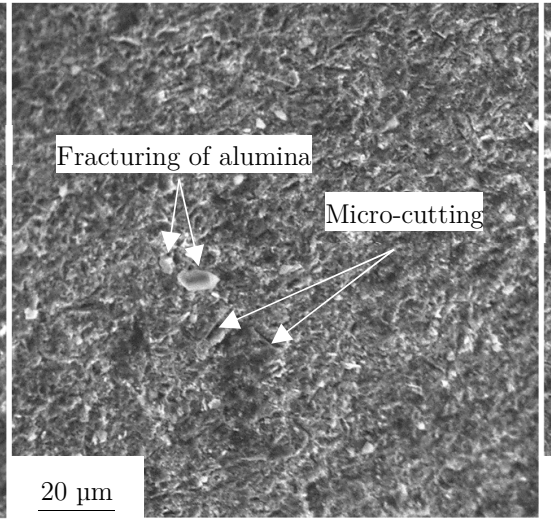

(b)

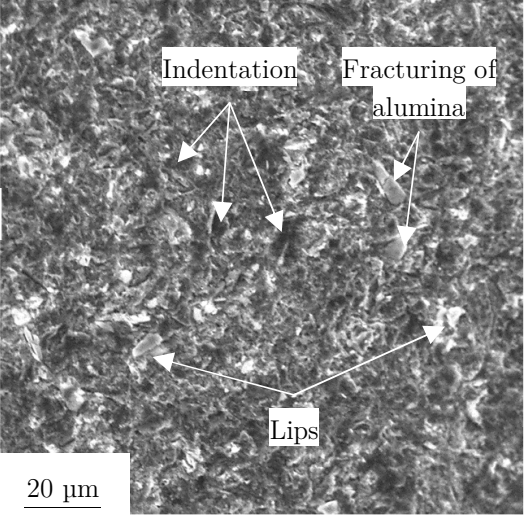

(c)

Fig. 11. SEM investigation of the eroded optimum $\mathrm{HVOF}$ NiCrSiB- $\mathrm{Al}_{2} \mathrm{O}_{3}$ deposition showing (a) eroded specimen at $30^{\circ}$, (b) $60^{\circ}$ and (c) $90^{\circ}$ erodent stream angle.

Overall, the erosion mechanism associated with optimally coated HVOF NiCrSiB- $\mathrm{Al}_{2} \mathrm{O}_{3}$ deposition involves micro-ploughing and cutting, crater, grooves, extruded lips resulting in fracturing and pull out of the alumina particle. While these mechanisms are often seen in both ductile and brittle wear modes; ductile erosion was found to be the dominant case in this study. Based on the influence of 
the erodent stream angle, a $90^{\circ}$ showed superior wear resistance in comparison to other angles tested. This is primarily due to the presence of high volumes of metallic phase in the deposition. Even though shear failure was observed at lower erodent angles, fatigue, micro-forging, and extrusion were the results of the higher erodent angles. The compressive force at higher erodent angles $\left(90^{\circ}\right)$ was found to be less detrimental to erosion resistance and resulted in lower wear damage in comparison to severe cutting and ploughing at lower impact angles.

The study shows that HVOF thermal spraying can result in high-density $\mathrm{NiCrSiB}-\mathrm{Al}_{2} \mathrm{O}_{3}$ coatings with low porosity, high hardness, and low EWL by optimisation of the process variables. Even though excellent characteristics of HVOF coatings were observed, further studies considering a large variety of suitable materials and different HVOF sub-processes are required to tailor coatings for a broad range of application. Nevertheless, the study makes it evident that the HVOF process parameter optimisation is critical to enhancing coating performance.

\section{Conclusions}

Parametric analysis of the HVOF process parameters required for the deposition of 60:40 wt.\% ratio of $\mathrm{NiCrSiB}-\mathrm{Al}_{2} \mathrm{O}_{3}$ coating on AISI304 substrate was conducted. Consequently, the optimum process parameters for minimum Erosion Wear Loss (EWL) were found to be $260 \mathrm{lpm}\left(Q_{\text {oxy }}\right), 65 \mathrm{lpm}$ $\left(Q_{\text {fuel }}\right), 28 \mathrm{~g} / \mathrm{min}\left(\dot{m}_{\text {feed }}\right)$ and $250 \mathrm{~mm}\left(D_{\text {sof }}\right)$, flow rate of oxygen, fuel, feed rate of powder and, standoff distance respectively. The optimisation algorithm identified the parametric 'order of importance' as $\dot{m}_{\text {feed }}>D_{\text {sof }}>Q_{o x y}>Q_{\text {fuel }}$. The analysis of variance resulted in $\dot{m}_{\text {feed }}$ having the highest significance to erosion loss at $53 \%$ followed by $D_{\text {sof }}$ at $24 \%$ at a confidence interval of $92.6 \%$ considering both individual and interaction effects of the HVOF process parameters. A DoE based prediction model for the EWL of the coating combining the four process parameters within the specified levels were derived. Subsequent experimental validation of the prediction model using optimum parametric combination resulted in a good agreement while quantifying the EWL at an error margin of $4.89 \%$. Evaluation of the $\mathrm{NiCrSiB}-\mathrm{Al}_{2} \mathrm{O}_{3}$ coating under optimal HVOF parameters showed high hardness $\left(843 \mathrm{HV}_{0.3}\right)$ and low porosity (1.5\%). Furthermore, the erosion tests on the optimal coating showed a 1.6 times higher wear resistance at an erodent stream impact angle of $90^{\circ}$ in comparison to $30^{\circ}$. Studying the mechanism of erosion on the optimal coating, both ductile and brittle wear were observed involving micro-ploughing, micro-cutting, crater, grooves, extruded lips combined with $\mathrm{Al}_{2} \mathrm{O}_{3}$ pull-out and fracture. While further work on sub-level process optimisation in combination with powder morphology is necessary, this paper presents an optimal case considering the most significant HVOF process parameters for an effective deposition of $\mathrm{NiCrSiB}-\mathrm{Al}_{2} \mathrm{O}_{3}$ on AISI304 steel. 


\section{Data availability}

The data that support the findings of this study are available from the corresponding author upon reasonable request.

\section{References}

[1] J. Saaedi, T.W. Coyle, H. Arabi, S. Mirdamadi, J. Mostaghimi, Effects of HVOF process parameters on the properties of Ni-Cr coatings, J. Therm. Spray Technol. 19 (2010) 521-530. doi:10.1007/s11666-009-9464-5.

[2] J.M. Miguel, J.M. Guilemany, S. Vizcaino, Tribological study of NiCrBSi coating obtained by different processes, Tribol. Int. 36 (2003) 181-187. doi:10.1016/S0301-679X(02)00144-5.

[3] N. Serres, F. Hlawka, S. Costil, C. Langlade, F. Machi, A. Cornet, Dry coatings and ecodesign part. 1 Environmental performances and chemical properties, Surf. Coatings Technol. 204 (2009) 187-196. doi:10.1016/j.surfcoat.2009.07.012.

[4] Y. Kawahara, Application of High Temperature Corrosion-Resistant Materials and Coatings Under Severe Corrosive Environment in Waste-to-Energy Boilers, J. Therm. Spray Technol. 16 (2007) 202-213. doi:10.1007/s11666-006-9012-5.

[5] K. Simunovic, T. Saric, G. Simunovic, Different Approaches to the Investigation and Testing of the Ni-Based Self-Fluxing Alloy Coatings-A Review. Part 1: General Facts, Wear and Corrosion Investigations, Tribol. Trans. 57 (2014) 955-979. doi:10.1080/10402004.2014.927547.

[6] M.J. Tobar, C. Álvarez, J.M. Amado, G. Rodríguez, A. Yáñez, Morphology and characterization of laser clad composite NiCrBSi - WC coatings on stainless steel, 200 (2006) 6313-6317. doi:10.1016/j.surfcoat.2005.11.093.

[7] S. Harsha, D.K. Dwivedi, a. Agarwal, Influence of $\mathrm{CrC}$ addition in Ni-Cr-Si-B flame sprayed coatings on microstructure, microhardness and wear behaviour, Int. J. Adv. Manuf. Technol. 38 (2008) 93-101. doi:10.1007/s00170-007-1072-2.

[8] B. Cai, Y.F. Tan, L. He, H. Tan, L. Gao, Tribological properties of TiC particles reinforced Ni-based alloy composite coatings, Trans. Nonferrous Met. Soc. China (English Ed. 23 (2013) 1681-1688. doi:10.1016/S10036326(13)62648-5.

[9] a. Määttä, U. Kanerva, P. Vuoristo, Structure and tribological characteristics of HVOF coatings sprayed from powder blends of Cr 3C 2-25NiCr and NiCrBSi alloy, J. Therm. Spray Technol. 20 (2011) 366-371. doi:10.1007/s11666-010-9579-8.

[10] L. He, Y. Tan, X. Wang, T. Xu, X. Hong, Microstructure and wear properties of Al2O3-CeO2/Ni-base alloy composite coatings on aluminum alloys by plasma spray, Appl. Surf. Sci. 314 (2014) 760-767. doi:10.1016/j.apsusc.2014.07.047.

[11] F. Liu, M. Fang, Z. Huang, Y. Liu, S. Huang, Preparation and mechanical properties of NiCr - Al $2 \mathrm{O} 3-\mathrm{ZrO}$ 2 ( 8Y ) ceramic composites, Mater. Sci. Eng. A. 554 (2012) 1-5. doi:10.1016/j.msea.2012.05.004.

[12] Q.Y. Hou, Z. Huang, J.T. Wang, Influence of nano-Al2O3 particles on the microstructure and wear resistance of the nickel-based alloy coating deposited by plasma transferred arc overlay welding, Surf. Coatings Technol. 205 (2011) 2806-2812. doi:10.1016/j.surfcoat.2010.10.047.

[13] H.S. Grewal, H. Singh, A. Agrawal, Microstructural and mechanical characterization of thermal sprayed nickelalumina composite coatings, Surf. Coatings Technol. 216 (2013) 78-92. doi:10.1016/j.surfcoat.2012.11.029.

[14] L. Pawlowski, The Science and Engineering of Thermal Spray Coatings: Second Edition, 2008. doi:10.1002/9780470754085.

[15] S. Somiya, Y. Ito, Heat-Resistant Coating Technology for Gas Turbines, Handb. Adv. Ceram. (2013) 789-806. doi:10.1016/B978-0-12-385469-8.00043-5.

[16] O. Maranho, D. Rodrigues, M. Boccalini, a. Sinatora, Influence of parameters of the HVOF thermal spray process on the properties of multicomponent white cast iron coatings, Surf. Coatings Technol. 202 (2008) 34943500. doi:10.1016/j.surfcoat.2007.12.026. 
[17] M. Mohammadi, S. Javadpour, S. a J. Jahromi, K. Shirvani, a. Kobayashi, Characterization and hot corrosion performance of LVPS and HVOF-CoNiCrAlYSi coatings, Vacuum. 86 (2012) 1458-1464.

doi:10.1016/j.vacuum.2012.02.030.

[18] M.R. Ramesh, S. Prakash, S.K. Nath, P.K. Sapra, B. Venkataraman, Solid particle erosion of HVOF sprayed WC-Co/NiCrFeSiB coatings, Wear. 269 (2010) 197-205. doi:10.1016/j.wear.2010.03.019.

[19] S. Vignesh, K. Shanmugam, V. Balasubramanian, K. Sridhar, Identifying the optimal HVOF spray parameters to attain minimum porosity and maximum hardness in iron based amorphous metallic coatings, Def. Technol. 13 (2017) 101-110. doi:10.1016/J.DT.2017.03.001.

[20] S. Hong, Y. Wu, B. Wang, Y. Zheng, W. Gao, G. Li, High-velocity oxygen-fuel spray parameter optimization of nanostructured WC-10Co-4Cr coatings and sliding wear behavior of the optimized coating, Mater. Des. 55 (2014) 286-291. doi:10.1016/j.matdes.2013.10.002.

[21] M. Cherigui, H.. Feraoun, N.. Feninehe, H. Aourag, C. Coddet, Structure of amorphous iron-based coatings processed by HVOF and APS thermally spraying, Mater. Chem. Phys. 85 (2004) 113-119. doi:10.1016/j.matchemphys.2003.12.017.

[22] X. Guo, M. Planche, J. Chen, H. Liao, Relationships between in-flight particle characteristics and properties of HVOF sprayed WC-CoCr coatings, J. Mater. Process. Tech. 214 (2014) 456-461. doi:10.1016/j.jmatprotec.2013.09.029.

[23] M. Benegra, A.L.B. Santana, O. Maranho, G. Pintaude, Effect of Heat Treatment on Wear Resistance of Nickel Aluminide Coatings Deposited by HVOF and PTA, J. Therm. Spray Technol. 24 (2015) 1111-1116. doi:10.1007/s11666-015-0266-7.

[24] P. Sassatelli, G. Bolelli, M. Lassinantti Gualtieri, E. Heinonen, M. Honkanen, L. Lusvarghi, T. Manfredini, R. Rigon, M. Vippola, Properties of HVOF-sprayed Stellite-6 coatings, Surf. Coatings Technol. 338 (2018) 45-62. doi:10.1016/j.surfcoat.2018.01.078.

[25] J.R. García, J.E. Fernández, J.M. Cuetos, F.G. Costales, Fatigue effect of WC coatings thermal sprayed by HVOF and laser treated, on medium carbon steel, Eng. Fail. Anal. 18 (2011) 1750-1760. doi:10.1016/j.engfailanal.2011.03.026.

[26] J. Yuan, C. Ma, S. Yang, Z. Yu, H. Li, Improving the wear resistance of HVOF sprayed WC-Co coatings by adding submicron-sized WC particles at the splats' interfaces, Surf. Coatings Technol. 285 (2016) 17-23. doi:10.1016/j.surfcoat.2015.11.017.

[27] F. Ghadami, A.S.R. Aghdam, Improvement of high velocity oxy-fuel spray coatings by thermal post-treatments: A critical review, Thin Solid Films. (2019). doi:10.1016/J.TSF.2019.02.019.

[28] A. Arjunan, A. Baroutaji, A.S. Praveen, A.G. Olabi, C.J. Wang, Acoustic Performance of Metallic Foams, in: Ref. Modul. Mater. Sci. Mater. Eng., Elsevier, 2019. doi:10.1016/B978-0-12-803581-8.11561-9.

[29] A. Baroutaji, A. Arjunan, A. Niknejad, T. Tran, A.-G. Olabi, Application of Cellular Material in Crashworthiness Applications: An Overview, in: Ref. Modul. Mater. Sci. Mater. Eng., Elsevier, 2019. doi:10.1016/B978-0-12-803581-8.09268-7.

[30] A. Arjunan, Acoustic absorption of passive destructive interference cavities, Mater. Today Commun. 19 (2019) 68-75. doi:10.1016/j.mtcomm.2018.12.012.

[31] A. Arjunan, Targeted sound attenuation capacity of 3D printed noise cancelling waveguides, Appl. Acoust. 151 (2019) 30-44. doi:10.1016/J.APACOUST.2019.03.008.

[32] D.C. Montgomery, Design and Analysis of Experiments, John Wiley \& Sons, 2006.

[33] W.C. Lih, S.H. Yang, C.Y. Su, S.C. Huang, I.C. Hsu, M.S. Leu, Effects of process parameters on molten particle speed and surface temperature and the properties of HVOF CrC/NiCr coatings, Surf. Coatings Technol. 133-134 (2000) 54-60. doi:10.1016/S0257-8972(00)00873-2.

[34] M. Hasan, J. Stokes, L. Looney, M.S.J. Hashmi, Effect of spray parameters on residual stress build-up of HVOF sprayed aluminium/tool-steel functionally graded coatings, Surf. Coatings Technol. 202 (2008) 4006-4010. doi:10.1016/j.surfcoat.2008.02.016.

[35] W. Fang, T.Y. Cho, J.H. Yoon, K.O. Song, S.K. Hur, S.J. Youn, H.G. Chun, Processing optimization, surface properties and wear behavior of HVOF spraying WC-CrC-Ni coating, J. Mater. Process. Technol. 209 (2009) 3561-3567. doi:10.1016/j.jmatprotec.2008.08.024.

[36] Q. Wang, Z. Chen, L. Li, G. Yang, The parameters optimization and abrasion wear mechanism of liquid fuel 
HVOF sprayed bimodal WC-12Co coating, Surf. Coatings Technol. 206 (2012) 2233-2241.

doi:10.1016/j.surfcoat.2011.09.071.

[37] K. Murugan, A. Ragupathy, V. Balasubramanian, K. Sridhar, Optimizing HVOF spray process parameters to attain minimum porosity and maximum hardness in $\mathrm{WC}-10 \mathrm{Co}-4 \mathrm{Cr}$ coatings, Surf. Coat. Technol. 247 (2014) 90-102. doi:10.1016/j.surfcoat.2014.03.022.

[38] Y. Qin, Y. Wu, J. Zhang, S. Hong, W. Guo, L. Chen, H. Liu, Optimization of the HOVF Spray Parameters by Taguchi Method for High Corrosion-Resistant Fe-Based Coatings, J. Mater. Eng. Perform. 24 (2015) 2637-2644. doi:10.1007/s11665-015-1536-8.

[39] H. Amel-Farzad, E. Taheri-Nassaj, D. Meertens, R.E. Dunin-Borkowski, A.H. Tavabi, Low temperature pressureless immediate sintering of novel nanostructured WC/Co/NiCrSiB-alloy cemented carbide, (2017). http://arxiv.org/abs/1706.03426 (accessed February 26, 2019).

[40] A.S. Praveen, J. Sarangan, S. Suresh, J. Siva Subramanian, Erosion wear behaviour of plasma sprayed NiCrSiB/Al2O3 composite coating, Int. J. Refract. Met. Hard Mater. 52 (2015) 209-218. doi:10.1016/j.ijrmhm.2015.06.005.

[41] P. Crook, H.N. Farmer, Friction and wear of hardfacing alloys, ASM Handb. 18 (1992) 758-765.

[42] R. Kaul, P. Ganesh, S.K. Albert, A. Jaiswal, N.P. Lalla, A. Gupta, C.P. Paul, A.K. Nath, Laser cladding of austenitic stainless steel with nickel base hardfacing alloy, Surf. Eng. 19 (2003) 269-273. doi:10.1179/026708403322499182.

[43] M. Oksa, E. Turunen, T. Suhonen, T. Varis, S.-P. Hannula, M. Oksa, E. Turunen, T. Suhonen, T. Varis, S.-P. Hannula, Optimization and Characterization of High Velocity Oxy-fuel Sprayed Coatings: Techniques, Materials, and Applications, Coatings. 1 (2011) 17-52. doi:10.3390/coatings1010017.

[44] W. Fang, T.Y. Cho, J.H. Yoon, K.O. Song, S.K. Hur, S.J. Youn, H.G. Chun, Processing optimization, surface properties and wear behavior of HVOF spraying WC-CrC-Ni coating, J. Mater. Process. Technol. 209 (2009) 3561-3567. doi:http://dx.doi.org/10.1016/j.jmatprotec.2008.08.024.

[45] R.A. Mahesh, R. Jayaganthan, S. Prakash, A study on the oxidation behavior of HVOF sprayed NiCrAlY -0 . 4 wt .\% CeO 2 coatings on superalloys at elevated temperature, 119 (2010) 449-457. doi:10.1016/j.matchemphys.2009.09.024.

[46] W. Zórawski, S.J. Skrzypek, Tribological properties of plasma and HVOF-sprayed NiCrBSi-Fe2O3 composite coatings, Surf. Coatings Technol. 220 (2013) 282-289. doi:10.1016/j.surfcoat.2012.09.057.

[47] E. Turunen, T. Varis, T.E. Gustafsson, J. Keskinen, T. Fält, S.P. Hannula, Parameter optimization of HVOF sprayed nanostructured alumina and alumina-nickel composite coatings, Surf. Coatings Technol. 200 (2006) 4987-4994. doi:10.1016/j.surfcoat.2005.05.018.

[48] L. Zhao, J. Zwick, E. Lugscheider, HVOF spraying of Al2O3-dispersion-strengthened NiCr powders, Surf. Coatings Technol. 182 (2004) 72-77. doi:10.1016/S0257-8972(03)00874-0.

[49] L. Zhao, M. Parco, E. Lugscheider, Wear behaviour of Al 2 O 3 dispersion strengthened MCrAlY coating, 184 (2004) 298-306. doi:10.1016/j.surfcoat.2003.10.055.

[50] A. G76-18, Standard Test Method for Conducting Erosion Tests by Solid Particle Impingement Using Gas Jets, (2018). doi:10.1520/G0076-18.

[51] A. Vance, K. Bari, A. Arjunan, Investigation of Ti64 sheathed cellular anatomical structure as a tibia implant, Biomed. Phys. Eng. Express. 5 (2019) 035008. doi:10.1088/2057-1976/ab0bd7.

[52] K. Bari, A. Arjunan, Extra low interstitial titanium based fully porous morphological bone scaffolds manufactured using selective laser melting, J. Mech. Behav. Biomed. Mater. 95 (2019) 1-12. doi:10.1016/j.jmbbm.2019.03.025.

[53] A. Vance, K. Bari, A. Arjunan, Compressive performance of an arbitrary stiffness matched anatomical Ti64 implant manufactured using Direct Metal Laser Sintering, Mater. Des. 160 (2018) 1281-1294. doi:10.1016/j.matdes.2018.11.005.

[54] J. a. Picas, M. Punset, M.T. Baile, E. Martín, a. Forn, Effect of oxygen/fuel ratio on the in-flight particle parameters and properties of HVOF WC-CoCr coatings, Surf. Coatings Technol. 205 (2011) S364-S368. doi:10.1016/j.surfcoat.2011.03.129.

[55] K. Murugan, a Ragupathy, V. Balasubramanian, K. Sridhar, Developing Empirical Relationship to Predict Hardness in WC- 10Co-4Cr HVOF Sprayed Coatings, 5 (2014) 918-927. doi:10.1016/j.mspro.2014.07.379. 
[56] V. V Sobolev, J.M. Guilemany, Investigation of coating porosity formation during high velocity oxy-fuel (HVOF) spraying, Mater. Lett. 18 (1994) 304-308.

[57] M.P. Planche, H. Liao, B. Normand, C. Coddet, Relationships between NiCrBSi particle characteristics and corresponding coating properties using different thermal spraying processes, Surf. Coatings Technol. 200 (2005) 2465-2473. doi:10.1016/j.surfcoat.2004.08.224.

[58] H.X. Hu, S.L. Jiang, Y.S. Tao, T.Y. Xiong, Y.G. Zheng, Cavitation erosion and jet impingement erosion mechanism of cold sprayed Ni-Al $\quad 2 \mathrm{O} \quad 3$ coating, Nucl. Eng. Des. 241 (2011) 49294937. doi:10.1016/j.nucengdes.2011.09.038.

[59] W.Y. Li, C. Zhang, H. Liao, J. Li, C. Coddet, Characterizations of cold-sprayed Nickel-Alumina composite coating with relatively large Nickel-coated Alumina powder, Surf. Coatings Technol. 202 (2008) 4855-4860. doi:10.1016/j.surfcoat.2008.04.076.

[60] G. Bolelli, V. Cannillo, L. Lusvarghi, M. Montorsi, F.P. Mantini, M. Barletta, Microstructural and tribological comparison of HVOF-sprayed and post-treated M-Mo-Cr-Si (M=Co, Ni) alloy coatings, Wear. 263 (2007) 1397-1416. doi:10.1016/j.wear.2006.12.002.

[61] J. Suutala, J. Tuominen, P. Vuoristo, Laser-assisted spraying and laser treatment of thermally sprayed coatings, Surf. Coatings Technol. 201 (2006) 1981-1987. doi:10.1016/j.surfcoat.2006.04.042.

[62] M.. Uusitalo, P.M.. Vuoristo, T.. Mäntylä, High temperature corrosion of coatings and boiler steels in reducing chlorine-containing atmosphere, Surf. Coatings Technol. 161 (2002) 275-285. doi:10.1016/S0257-8972(02)004723.

[63] J.R. Laguna-Camacho, a. Marquina-Chávez, J. V. Méndez-Méndez, M. Vite-Torres, E. a. Gallardo-Hernández, Solid particle erosion of AISI 304, 316 and 420 stainless steels, Wear. 301 (2013) 398-405. doi:10.1016/j.wear.2012.12.047.

[64] S. Bhandari, H. Singh, H.K. Kansal, V. Rastogi, Slurry erosion behaviour of detonation gun spray Al $2 \mathrm{O} 3$ and Al 20 3-13TiO 2-coated CF8M steel under hydro accelerated conditions, Tribol. Lett. 45 (2012) 319-331. doi:10.1007/s11249-011-9891-6.

[65] R. Ahmed, Contact fatigue failure modes of HVOF coatings, 2002. http://home.eps.hw.ac.uk/ mcera/Publications/Journal-Papers/WEAR-RA-2002-Vol253-2.pdf (accessed March 7, 2019). 